\title{
Maximizar la terapia de exposición: Un enfoque basado en el aprendizaje inhibitorio*
}

\author{
David Torrents-Rodas ${ }^{1}$, Miquel A. Fullana ${ }^{1,2}$, Bram Vervliet ${ }^{3}$, Michael Treanor ${ }^{4}$, Chris Conway ${ }^{4}$, \\ Tomislav Zbozinek ${ }^{4}$ y Michelle G. Craske ${ }^{4}$ \\ ${ }^{1}$ Universidad Autónoma de Barcelona, Barcelona, España. \\ ${ }^{2}$ Parc de Salut Mar, Barcelona, España \\ ${ }^{3}$ KU Leuven-University of Leuven, Leuven, Bélgica \\ ${ }^{4}$ University of California, Los Angeles, USA
}

Resumen: A pesar de la efectividad de la terapia de exposición para el tratamiento de los trastornos de ansiedad, algunos pacientes no se benefician de ella o experimentan un retorno del miedo después del tratamiento. La investigación sugiere que las personas con ansiedad presentan déficits en los mecanismos supuestamente implicados en la terapia de exposición, como el aprendizaje inhibitorio. Centrarse en estos mecanismos podría mejorar la eficacia de los procedimientos basados en la exposición. El principal objetivo de este artículo es proporcionar ejemplos a los clínicos sobre cómo optimizar la terapia de exposición aplicando el modelo de aprendizaje inhibitiorio. Las estrategias de optimización incluyen 1) violación de expectativas, 2) extinción intensificada, 3) refuerzo ocasional durante la extinción, 4) retirada de señales de seguridad, 5) variabilidad, 6) claves de recuperación, 7) contextos múltiples y 8) etiquetado de las emociones. Mediante estudios de caso se mostrarán formas de aplicar estas técnicas en varios trastornos de ansiedad.

Palabras clave: Aprendizaje inhibitorio; terapia de exposición; trastorno obsesivo-compulsivo; trastorno de estrés postraumático; fobia social; fobia específica; trastorno de pánico.

\section{Maximizing exposure therapy: An inhibitory learning approach}

\begin{abstract}
Despite the effectiveness of exposure therapy for treating anxiety disorders, a number of patients fail to benefit or experience a return of fear after treatment. Research suggests that anxious individuals show deficits in the mechanisms believed to underlie exposure therapy, such as inhibitory learning. Targeting these processes may help improve the efficacy of exposure-based procedures. The primary aim of this paper is to provide examples to clinicians for how to apply this model to optimize exposure therapy with anxious clients, in ways that distinguish it from a "fear habituation" approach and "belief disconfirmation" approach within standard cognitive-behavior therapy. Exposure optimization strategies include 1) expectancy violation, 2) deepened extinction, 3) occasional reinforced extinction, 4) removal of safety signals, 5) variability, 6) retrieval cues, 7) multiple contexts, and 8) affect labeling. Case studies illustrate methods of applying these techniques with a variety of anxiety disorders.
\end{abstract}

Keywords: Inhibitory learning; exposure therapy; obsessive-compulsive disorder; posttraumatic stress disorder; social phobia; specific phobia; panic disorder.

La terapia de exposición, o la confrontación repetida de los estímulos que provocan miedo, ha sido la base fun- damental de la terapia cognitivo-conductual para los trastornos de ansiedad desde sus inicios. La exposición toma
Recibido: 28 octubre 2014; aceptado: 10 noviembre 2014. Correspondencia: Michelle G. Craske, PhD., Department of Psychology, UCLA, 405 Hilgard Avenue, Los Angeles, CA 90095-1563. Correo-e: craske@psych.ucla.edu. Tel.: +1 (310) 8258403. Agradecimientos: Los autores quieren agradecer los comentarios en la fase de preparación del manuscrito de Katharina Kircanski.
* Traducción al español del artículo: Craske, M.G., Treanor, M., Conway, C., Zbozinek, T, \& Vervliet, B. (2014). Maximizing exposure therapy: An inhibitory learning approach. Behaviour Research and Therapy, 50, 10-23. Traducción autorizada por la autora principal (MGC). 
varias formas, incluyendo gradual versus intensiva (terapia de inundación), breve versus prolongada, con o sin estrategias de afrontamiento (revisadas por Meuret, Wolitzky-Taylor, Twohig, y Craske, 2012), e imaginada, interoceptiva o en vivo (en la vida real). La terapia de exposición ha demostrado ser una estrategia efectiva para el tratamiento de los trastornos de ansiedad (Hofmann y Smits, 2008; Norton y Price, 2007). Nuestra comprensión de los mecanismos responsables de los efectos de la terapia de exposición ha evolucionado a lo largo de los años (véase Craske et al., 2008; Craske, Liao, Brown, y Verliet, 2012). Los objetivos del presente artículo son repasar el modelo de aprendizaje inhibitorio de la extinción como mecanismo de la terapia de exposición para el miedo y la ansiedad, y explicar la aplicación clínica de este modelo. Su aplicación se presenta en un listado de estrategias conductuales específicas, acompañadas por su descripción en el contexto de estudios de caso en los trastornos de pánico/agorafobia, ansiedad social, estrés postraumático, obsesivo-compulsivo y fobia específica. Otros enfoques de la terapia de exposición incluyen los modelos basados en la habituación, que enfatizan la reducción del miedo mediante la exposición, y los experimentos conductuales dirigidos a desconfirmar creencias y suposiciones de contenido amenazante (Foa y Kozak, 1986; Foa y McNally, 1996; Salkovskis, Hackmann, Wells, Gelder, y Clark, 2006). En artículos previos, hemos comparado el modelo de aprendizaje inhibitorio con los modelos de habituación del miedo y de desconfirmación de creencias mediante experimentos conductuales (i.e., Craske et al., 2008; Craske et al., 2012). En la discusión que sigue, presentamos aplicaciones específicas de las distintas formas en que el modelo de aprendizaje inhibitorio se distingue de los otros modelos.

\section{Modelo de aprendizaje inhibitorio de la extinción}

Según el modelo de condicionamiento pavloviano, un estímulo neutro (el estímulo condicionado, EC; por ejemplo, una imagen neutra) va seguido de un estímulo aversivo (el estímulo incondicionado, EI; por ejemplo, un estímulo eléctrico). Después de un cierto número de emparejamientos, el EC neutro será capaz de producir reacciones anticipatorias de miedo (respuesta condicionada, RC). La RC se produce porqué el EC pasa a ser un predictor del EI. Se ha postulado que existe una asociación entre las representaciones mnemónicas del EC y el EI, de modo que las presentaciones del EC activan indirectamente la memoria del EI, pudiéndose producir miedo por el hecho de "pensar" en el EI aversivo. El condicionamiento del miedo se considera un modelo válido para muchos de los trastornos de ansiedad, incluyendo el trastorno de pánico, el trastorno de ansiedad social, la fobia específica, el trastorno obsesivo-compulsivo, y el trastorno de estrés postraumático (Grillon, 2008). En la extinción, el EC se presenta repetidas veces en ausencia del evento aversivo asociado (el EI), siendo ésta una potente forma de reducir las reacciones condicionadas de miedo. La terapia de exposición, en la que una persona se expone repetidamente a los estímulos que le producen miedo en ausencia de las consecuencias aversivas, es la forma clínica de la extinción. De hecho, la terapia de exposición, formulada por primera vez por Wolpe (1959) en forma de desensibilización sistemática, fue derivada de los primeros modelos de aprendizaje de extinción.

El aprendizaje inhibitorio se considera un mecanismo central de la extinción (Bouton, 1993; Miller y Matzel, 1988; Wagner, 1981), aunque otros mecanismos, como la habituación, también pueden estar implicados (Myers y Davis, 2007). Dentro del enfoque del condicionamiento pavloviano, los modelos inhibitorios de aprendizaje proponen que la asociación EC-EI original, aprendida durante el condicionamiento del miedo, no se borra durante la extinción, sino que permanece intacta mientras se desarrolla un nuevo -y secundario- aprendizaje inhibitorio sobre el EC-EI (concretamente, que el EC ya no predice el EI; véase por ejemplo, Bouton, 1993; Bouton y King, 1983). La investigación sobre los mecanismos neurales que subyacen a la extinción del miedo apoyan un modelo inhibitorio, dado que la amígdala, que se activa especialmente durante el condicionamiento del miedo (Shin y Liberzon, 2010), se ve inhibida por influencias corticales (en concreto, de la corteza prefrontal medial) lo que da lugar al aprendizaje de extinción (Milad et al., 2007; Milad et al., 2009).

Bouton y sus colegas proponen que después de la extinción, el EC tiene dos significados; su significado excitatorio original (EC-EI) y un significado inhibitorio adicional (EC-noEI). Por tanto, a pesar de que el miedo disminuye con suficientes presentaciones del EC en ausencia del EI, la retención de parte de la asociación original puede revelarse mediante varios procedimientos, cada uno de los cuales muestra el efecto persistente de la asociación excitatoria original después de la extinción. En primer lugar, el miedo condicionado muestra recuperación espontánea (Quirk, 2002), lo que implica que la fuerza de la respuesta condicionada aumenta de forma proporcional a la cantidad de tiempo transcurrido desde la extinción. A nivel clínico, este efecto se refleja en el retorno del miedo, que ocurre a menudo con el paso del tiempo desde la finalización de la terapia de exposición (véase por ejemplo, Craske y Mystkowski, 2006; Craske y Rachman, 1986). Así, una persona cuyo miedo a volar se reduce significativamente al final de un tratamiento de 
exposición es vulnerable al retorno del miedo si no realiza viajes en avión durante un tiempo.

En segundo lugar, se produce renovación del miedo condicionado si hay un cambio de contexto de la extinción posteriormente (Bouton, 1993). En otras palabras, la extinción del miedo parece ser específica del contexto en que se lleva a cabo. Estos efectos han sido observados en muestras análogas que siguieron un tratamiento de exposición y un test de seguimiento en el mismo o en distintos contextos (Culver, Stoyanova y Craske, 2011; Mystkowski, Craske, y Echiverri, 2002; Mystkowski, Craske, Echiverri, y Labus, 2006; Mystkowski, Mineka, Vernon, y Zinbarg, 2003). La importancia clínica de la renovación se manifiesta cuando la terapia de exposición se lleva a cabo en un único contexto, o en un número limitado de estos, de modo que el miedo es susceptible de reaparecer cuando se encuentra de nuevo el estímulo fóbico en un contexto distinto (por ejemplo cuando la personas está sola o en un contexto que no guarda ninguna relación con una sesión de terapia).

En tercer lugar, se produce restablecimiento ("reinstatement") del miedo condicionado cuando se presentan EI no señalados (no emparejados) entre la extinción y el retest (Hermans et al., 2005; Rescorla y Heth, 1975; Van Damme, Crombez, Hermans, Koster, y Eccleston, 2006). La implicación clínica del restablecimiento es que los eventos adversos que ocurren después de la terapia pueden hacer reaparecer el miedo al estímulo previamente temido si la persona encuentra éste en un contexto ansiógeno. Por ejemplo, el miedo a hacer preguntas en reuniones de trabajo puede resurgir después del rechazo en otra situación social, o incluso después de otro evento adverso no relacionado (por ejemplo, un accidente de tráfico).

En cuarto lugar, se observa una rápida readquisición de la RC cuando se vuelven a repetir emparejamientos EC-EI después de la extinción. La implicación clínica es que los miedos que han disminuido pueden ser readquiridos rápidamente con la "retraumatización", como puede ocurrir en situaciones de combate $u$ otros entornos peligrosos.

\section{Déficits en inhibición y trastornos de ansiedad}

En un número substancial de personas las terapias basadas en la exposición no son completamente eficaces (Arch y Craske, 2009), o se experimenta un retorno del miedo después de la terapia (véase Craske y Mystkowski, 2006). Esto puede deberse en parte a déficits en el aprendizaje de extinción (Craske et al., 2008; Lissek et al., 2005) y, más específicamente, a los déficits en el aprendizaje inhibitorio y en la regulación neural inhibitoria durante la extinción, que caracterizan a las persona con tras- tornos de ansiedad o alta ansiedad rasgo (véase por ejemplo, Indovina, Robbins, Nunez-Elizalde, Dunn, y Bishop, 2011; Jovanovic et al., 2010; Milad et al., 2009; Milad et al., 2013; Rougemont-Bucking et al., 2011; para un resumen véase Craske et al., 2012). En otras palabras, las personas ansiosas muestran déficits en los mecanismos que supuestamente son centrales en el aprendizaje de exposición. Estos déficits no sólo pueden contribuir a una respuesta insuficiente a la terapia de exposición, sino también al desarrollo de miedo y ansiedad excesivos.

La optimización del aprendizaje inhibitorio durante la terapia de exposición tiene un gran valor clínico, tanto para potenciar la eficacia del tratamiento en general como para compensar los déficits presentes en las personas ansiosas. Un modelo de exposición que tenga en cuenta elementos de aprendizaje inhibitorio tiene el potencial de contrarrestar los efectos negativos de la recuperación espontánea, la renovación, el restablecimiento y la readquisición. El objetivo es potenciar el aprendizaje inhibitorio (y posiblemente la regulación neural subyacente) durante la terapia de exposición y potenciar su recuerdo después de esta.

\section{Aprendizaje inhibitorio versus los enfoques de habituación y comprobación conductual en la terapia de exposición}

Las estrategias que serán enumeradas más adelante no siempre son consistentes con un modelo de terapia de exposición basado en la habituación, que se basa en la reducción del miedo durante los ensayos de exposición como índice crítico del cambio terapéutico (e.g., Foa y Kozak, 1986; Foa y McNally, 1996; Lader y Matthews, 1978). Los modelos de habituación proponen que la reducción del miedo durante una sesión de exposición es un precursor necesario para cambios cognitivos posteriores, y más duraderos, en el peligro percibido asociado al estímulo fóbico. Las estrategias que se derivan de los modelos de aprendizaje inhibitorio no enfatizan la reducción del miedo en sí durante los ensayos de exposición, y en lugar de esto a veces utilizan estrategias diseñadas para mantener un miedo elevado durante estos ensayos. A favor de esta idea está el hecho que la magnitud de reducción del miedo al final de la extinción no predice la cantidad de miedo expresada en un test de recuerdo de la extinción, en muestras de laboratorio tanto animales como humanas (Plendl y Wotjak, 2010; Prenoveau, Craske, Liao, y Ornitz, 2013; Rescorla, 2006). De modo similar, la magnitud de reducción del miedo al final de una sesión de exposición, o una serie de sesiones de exposición, no predicen el nivel de miedo expresado en una sesión de seguimiento en personas con miedo 
(Baker et al., 2010; Culver, Stoyanova, y Craske, 2012; Kircanski et al., 2012). Estos hallazgos son consistentes con la noción de divergencia de los sistemas de respuesta, y con el hecho que la expresión manifiesta de miedo, por un lado, y las asociaciones condicionadas indicativas de aprendizaje, por el otro, no siempre cambian en concordancia (Beckers, Krypotos, Boddez, Effting, y Kindt, 2013). El miedo expresado en una evaluación de seguimiento (como índice clave de la fuerza y la consolidación del aprendizaje de extinción) parece estar más influido por factores como el paso del tiempo, los cambios de contexto, los eventos adversos, o el reaprendizaje que por el nivel de miedo experimentado al final de la extinción/exposición. Algunos aspectos del modelo de aprendizaje inhibitorio se solapan con modelos cognitivos que enfatizan el papel de los ensayos conductuales para desconfirmar creencias y asunciones (Salkovskis, Hackmann, Wells, Gelder, y Clark, 2006). Sin embargo, el modelo de aprendizaje inhibitorio no se restringe únicamente a la comprobación conductual como estrategia para generar asociaciones inhibitorias ni se limita a la comprobación de cogniciones explícitas.

\section{Estrategias terapéuticas para potenciar el aprendizaje inhibitorio y su recuperación}

(1) Violación de expectativas. La primera estrategia consiste en diseñar exposiciones que violen lo máximo posible las expectativas en relación a la frecuencia o la intensidad de las consecuencias aversivas (Davey, 1992; Gallistel y Gibbon, 2000; Rescorla y Wagner, 1972). Esta estrategia se deriva de la premisa que la discrepancia entre la expectativa y el resultado es crítica para que se produzca aprendizaje nuevo (Rescorla y Wagner, 1972) y para el desarrollo de expectativas inhibitorias que compitan con las expectativas excitatorias. Cuanto más se viole la expectativa mediante la experiencia, mayor será el aprendizaje inhibitorio. En la agorafobia, esta aproximación mostró el mismo beneficio a largo plazo con un solo ensayo de exposición en dos días que con ensayos de exposición repetidos cada día (Baker et al., 2010). Deacon et al. (2013) mostraron que la exposición interoceptiva que duraba hasta que las expectativas de una consecuencia aversiva disminuían a menos del 5\% era superior a una exposición interoceptiva estándar. Desde este enfoque, las tareas de exposición se diseñan para acomodar "qué es lo que necesitas aprender" en lugar de primar la reducción del miedo o "continúa en la situación hasta que el miedo disminuya", como se defendería desde un modelo de terapia de exposición basado en la habituación. Por ejemplo, en las personas que creen irracionalmente que la ansiedad prolongada puede cau- sarles algún "daño", se les induce ansiedad durante largos periodos para violar completamente sus expectativas. Desde un punto de vista clínico, es importante que el cliente identifique el EI cuando prediga la expectativa que tendrá que ser violada. Por ejemplo, en las personas con ansiedad social, no sería suficiente con predecir que se "pondrán nerviosos" durante una interacción social; en cambio, sí que bastaría con predecir que serán ignorados o rechazados. El enfoque de violación de expectativas liga directamente los parámetros de exposición con expectativas de eventos aversivos expresadas conscientemente. Como tal, se solapa con modelos en que la exposición se utiliza para desconfirmar creencias. En un estudio de Salkovskis et al. (2006) los modelos de desconfirmación de creencias fueron superiores a los enfoques de habituación. Además, en contra de los enfoques de habituación, hay evidencias de que ni la reducción ni la desaparición del miedo predicen los resultados a largo plazo de la extinción o la exposición (Baker et al., 2010; Culver et al., 2012; Kircanski et al., 2012; Plendl y Wotjak, 2010; Prenoveau et al., 2013; Rescorla, 2006 - discutido en secciones previas). En este sentido, existen datos que confirman que las estrategias de exposición que impiden de forma específica la habituación son más efectivas que las estrategias que no lo hacen (Culver et al., 2012; Kircanski et al., 2012; Lang y Craske, 2000 revisado en las siguientes secciones). Desde el enfoque de violación de expectativas, la duración de un ensayo de exposición se determina en función del tiempo que se considera necesario para violar las expectativas de forma más efectiva, en lugar de tener en cuenta la reducción del miedo. El aprendizaje se centra en el hecho de si la consecuencia negativa esperada ocurrió o no, o fue tan mala como se esperaba (i.e., fue tolerable o no). Así, después de cada ensayo de exposición, el aprendizaje se consolida preguntando a los participantes que juzguen lo que aprendieron en relación a la no-ocurrencia del evento temido, la discrepancia entre lo que predecían y lo que ocurrió, y el grado de "sorpresa" que les produjo la práctica de exposición (véase por ejemplo, Rescorla y Wagner, 1972). Por tanto, el repaso mental, o en este caso el repaso de la asociación inhibitoria EC-no EI, es un componente importante de la consolidación de la memoria (Joos, 2011; Meeter y Murre, 2004).

Un aspecto clave del modelo de violación de expectativas es facilitar la atención tanto al EC como a la no-ocurrencia del EI. Los modelos de corrección de errores (véase por ejemplo, Rescorla y Wagner, 1972) postulan un papel importante de la saliencia del EC, de modo que el cambio en la fuerza asociativa (por ejemplo, aprendizaje de extinción) se dirigirá al estímulo más saliente (Mackintosh, 1975; Pearce y Hall, 1980). En la 
medida que el aprendizaje de extinción representa la formación de una relación no-contingente entre el EC y el EI, la consciencia tanto del EC como de la no-ocurrencia del EI es crucial. Este podría ser uno de los motivos por los cuales la distracción es una conducta de seguridad tan perjudicial, dado que puede reducir la consciencia del EC, o de la relación EC-no EI ${ }^{1}$. También podría explicar las limitaciones de los modelos basados en la habituación, ya que se potencia la habituación mediante un procedimiento que puede reducir la saliencia del estímulo (i.e., exposición repetida al mismo estímulo). Más adelante volveremos a la importancia de la saliencia, cuando nos refiramos a la extinción ocasionalmente reforzada como estrategia para potenciar el aprendizaje inhibitorio.

Dentro del modelo de violación de expectativas, se puede utilizar la exposición graduada en condiciones en que la ocurrencia de la consecuencia temida se percibe como más probable (i.e., las condiciones que proporcionan una violación de expectativas óptima). En contraste con el modelo basado en la habituación, la aproximación graduada está ligada a las condiciones de violación per se (por ejemplo, duración de la exposición) y no necesariamente ligada al nivel de miedo (por ejemplo, repetir cada ítem de la jerarquía de miedo suficientes veces como para que el miedo disminuya antes de seguir al siguiente ítem). Por ejemplo, en las personas que temen tener un ataque al corazón durante un ataque de pánico dentro de un ascensor, la exposición puede realizarse en ensayos progresivamente más largos dentro del ascensor, a pesar de que el miedo no disminuya con cada ensayo. En particular, la activación sostenida a lo largo de la extinción se asocia a un menor miedo en un test posterior, tanto en animales (Rescorla, 2006) como en humanos (Culver, Stephans y Craske, en preparación-a), la activación consolida el recuerdo de la extinción (Cain, Blouin, y Barad, 2004) y, en algunos de nuestros estudios, la incapacidad de habituar el miedo a lo largo la terapia de exposición no se asocia a peores resultados (por ejemplo, Culver et al., 2012; Kircanski et al., 2012; Lang y Craske, 2000).

La premisa básica de la aproximación de violación de expectativas, i.e., que el aprendizaje de extinción se ve potenciado por la discrepancia entre las expectativas y la

${ }^{1}$ Hay que resaltar que un reciente metaanálisis sobre la distracción durante la exposición para las fobias específicas indicó que la exposición conseguía mejores resultados conductuales que la exposición con distracción pero, en determinadas condiciones de distracción interactiva y ensayos de exposición repetidos, la exposición con distracción conseguía mejores resultados a nivel conductual y emocional (Podina, Koster, Philippot, Dethier, y David, 2013). experiencia, implica que las estrategias que reducen las expectativas antes de la extinción pueden afectar de modo negativo al aprendizaje de extinción. Así, las intervenciones cognitivas diseñadas para disminuir la probabilidad de sobrestimación (por ejemplo, "es poco probable que me muerda un perro") y la valencia negativa percibida (por ejemplo, "no es tan malo que me rechacen") pueden perjudicar el aprendizaje inhibitorio cuando se emplean antes o durante las exposiciones. Las intervenciones cognitivas pueden reducir la expectativa de un resultado negativo antes de la exposición y, por tanto, atenuar la discrepancia entre la expectativa inicial y el resultado. Por tanto, actualmente limitamos nuestras intervenciones "cognitivas" al cuestionamiento posterior a la exposición, con la finalidad de facilitar la consolidación de la memoria.

Los enfoques de habituación en la exposición proponen que la exposición a un ítem determinado continúe el tiempo suficiente hasta que el miedo disminuya, y se haga el número de veces necesario para que el miedo se atenúe significativamente. Desde un modelo de aprendizaje inhibitorio, la exposición se hace durante el tiempo que se considera suficiente para llevar a cabo una comprobación adecuada de una expectativa declarada, y continúa el número de ocasiones necesario para que disminuyan las expectativas.

(2) Extinción intensificada. Una segunda estrategia es la "extinción intensificada" (Rescorla, 2000, 2006), en la que múltiples ECs se extinguen por separado antes de ser combinados durante la extinción o un estímulo previamente extinguido se empareja con un nuevo EC. Esta estrategia ha mostrado reducir la recuperación espontánea y el restablecimiento del miedo en animales (Rescorla, 2006) y humanos (Culver, Vervliet, y Craske, en preparación-b). Cuando es posible, combinamos múltiples estímulos (internos y/o externos) durante la terapia de exposición, después de haber practicado la exposición a cada estímulo por separado. Aun así, es importante que los estímulos predigan el mismo EI. Un ejemplo de extinción intensificada para el trastorno de pánico y la agorafobia es la exposición interoceptiva a sensaciones corporales temidas (como el consumo de cafeína), y la exposición en vivo a situaciones agorafóbicas externas (como comprar en un centro comercial abarrotado), seguidas de la inclusión de exposición interoceptiva durante la exposición en vivo (tomar café en un centro comercial; Barlow y Craske, 1994). Otro ejemplo sería exponer a un tipo concreto de araña, luego a otro tipo claramente distinto, seguido de una exposición a las dos arañas al mismo tiempo. Un tercer ejemplo sería exponer a un pensamiento obsesivo (como la obsesión de apuñalar a un ser querido), exponer a un estímulo que 
desencadena esos pensamientos (como un cuchillo en presencia de un ser querido), seguido de la exposición tanto a la obsesión como al cuchillo en presencia del ser querido. A pesar que se supone que la extinción intensificada ejerce sus efectos mediante el incremento de la violación de expectativas, el procedimiento se podría implementar sin preguntar a los clientes que identifiquen sus expectativas de antemano. Así, la extinción intensificada constituye un modo en que el enfoque del aprendizaje inhibitorio se extiende más allá de la comprobación conductual con el propósito de desconfirmación de creencias.

(3) Refuerzo ocasional durante la extinción. Una tercera estrategia que está acumulando evidencias a su favor en los estudios con humanos es el aprendizaje reforzado ocasionalmente durante la extinción. La extinción reforzada ocasionalmente implica emparejamientos ECEI ocasionales durante los ensayos de extinción (Bouton, Woods, y Pineno, 2004). Los beneficios pueden derivarse de un efecto de violación de expectativas, en el que es menos probable que el participante espere que la siguiente presentación del EC prediga el EI porqué los emparejamientos EC-EI han sido asociados tanto con más emparejamientos EC-EI como con emparejamientos EC-no EI (Bouton et al., 2004). Por otro lado, el refuerzo ocasional durante la extinción podría potenciar la saliencia del EC, que a su vez contribuiría a nuevos aprendizajes sobre éste (Pearce y Hall, 1980). De forma similar a los estudios con animales (Bouton et al., 2004), en un estudio de condicionamiento con humanos vimos que la extinción reforzada ocasionalmente mantenía la activación/miedo durante la extinción, pero atenuaba la siguiente readquisición de miedo (Culver et al., en preparación-a). El fenómeno de readquisición rápida es más probable en presencia de consecuencias aversivas repetidas (por ejemplo, rechazo social en el caso del trastorno de ansiedad social, y ataques de pánico en el caso del trastorno de pánico). También podría producirse en el contexto de entornos peligrosos que conduzcan a la retraumatización, aunque en estos casos la aproximación de la extinción reforzada ocasionalmente es éticamente reprobable. En el caso de la ansiedad social, un individuo podría extinguir con éxito el miedo frente situaciones sociales para luego experimentar un rápido retorno de la respuesta de miedo después de un único emparejamiento de una situación social con una consecuencia negativa (por ejemplo, rechazo o evaluación negativa). Aunque es necesario llevar a cabo más investigación, la translación clínica de la extinción ocasionalmente reforzada es la inclusión de rechazos sociales ocasionales y "ataques de vergüenza" en exposiciones a situaciones sociales, o la inducción deliberada de ataques de pánico (por ejemplo, mediante substancias como la yohimbina) en exposiciones a las situaciones temidas en el trastorno de pánico. Por los motivos expuestos, llevamos a cabo rutinariamente exposiciones reforzadas, e incluso animamos a los clientes a que busquen la oportunidad de recibir consecuencias negativas ocasionales. A pesar de que se supone que la extinción ocasionalmente reforzada produce sus efectos, al menos en parte, mediante una violación incrementada de las expectativas, este procedimiento se podría implementar sin pedir específicamente a los clientes que identifiquen sus expectativas de antemano. Así, la extinción ocasionalmente reforzada representa otra forma en que un enfoque de aprendizaje inhibitorio se extiende más allá de la comprobación conductual con el objetivo de desconfirmar creencias.

(4) Retirada de las señales de seguridad. Una cuarta estrategia es la retirada de "señales de seguridad" o prevención de "conductas de seguridad". Las señales y

conductas de seguridad típicas entre los clientes con ansiedad son la presencia de otra persona, los terapeutas, los teléfonos móviles, los medicamentos, el agua o otras bebidas. Para las personas que esperan consecuencias negativas contingentes al propio miedo (i.e., "miedo del miedo", como las personas con trastorno de pánico, que temen perder el control en el caso de experimentar un ataque de pánico; o las personas con ansiedad social, que temen la humillación en el caso de mostrar ansiedad), la reducción del miedo en sí misma podría convertirse en una señal de seguridad. En la literatura experimental, las señales de seguridad alivian el malestar a corto plazo, pero el miedo vuelve cuando éstas no siguen estando presentes (Lovibond, Davis y O'Flaherty, 2000). Se piensa que este efecto deriva en parte de la interferencia en el desarrollo de asociaciones inhibitorias. En muestras fóbicas, se ha visto que la disponibilidad y el uso de señales y conductas de seguridad es perjudicial para la terapia de exposición (Sloan y Telch, 2002), mientras que las instrucciones de no realizar conductas de seguridad mejoran los resultados (Salkovskis, 1991). Sin embargo, algunos datos recientes muestran hallazgos contradictorios (Rachman, Shafran, Radomsky, y Zysk, 2011). Concretamente, el uso de toallitas higiénicas después de exposiciones en individuos con miedo a la contaminación no condujo a mayor recuperación espontánea de miedo o asco que la exposición sin toallitas higiénicas. De modo similar, Deacon y colaboradores no han conseguido replicar los efectos perjudiciales de seguir realizando conductas de seguridad (incluyendo la disponibilidad de la conducta de seguridad pero sin llegar a llevarla a cabo) durante la exposición, en este caso en la claustrofobia (Deacon et al., 2010; Sy, Dixon, Lickel, Nelson, y Deacon, 2011). A pesar de ello, la capacidad 
de las conductas de seguridad de mitigar el aprendizaje de extinción probablemente varía en función de la "ratio" entre inhibición y extinción en un ensayo determinado. Es decir, la presencia de estímulos inhibitorios (i.e., estímulos que disminuyen la probabilidad de que se presente el EI) disminuirán el aprendizaje de extinción en la medida en que disminuyen la expectativa del EI, y la discrepancia entre lo que se predice y lo que ocurre en realidad determina el grado de cambio asociativo. Por tanto, el impacto de los estímulos inhibitorios en el aprendizaje de extinción dependerá del número y la fuerza de los estímulos inhibitorios versus el número y la fuerza de los estímulos excitatorios (i.e., estímulos que predicen el EI; Rescorla y Wagner, 1972). El consenso general sigue siendo que las señales o conductas de seguridad deberían ser abandonadas gradualmente a lo largo de la terapia de exposición (Hermans, Craske, Mineka, y Lovibond, 2006). La retirada gradual se recomienda solo para evitar el abandono del tratamiento. Si se está dispuesto, es preferible la retirada inmediata de las señales de seguridad.

(5) Variabilidad. Una quinta estrategia implica variabilidad de estímulos a lo largo de la exposición, ya que variar la tarea que hay que aprender potencia la retención del material no-emocional aprendido (Magill y Hall, 1990; Schmidt y Bjork, 1992, Shea y Morgan, 1979). Se cree que la variabilidad potencia la capacidad de almacenar la nueva información aprendida (Bjork y Bjork, 1992, 2006), conecta la información que hay que aprender con más claves de recuperación (Estes, 1955), o genera una regla que captura aquello común entre las distintas tareas (Schmidt y Bjork, 1992), lo que facilita la recuperación de la información más adelante. Aunque esta estrategia no se originó en los modelos de condicionamiento asociativo, los efectos también pueden explicarse mediante los modelos de recuperación del contexto de la extinción (Bouton, 1993), ya que es más probable que la variabilidad caracterice a los contextos en que se van a encontrar los estímulos fóbicos una vez que haya acabado la terapia de exposición. Así, la variabilidad durante la exposición puede contrarrestar a los efectos de la renovación después de la exposición. En muestras con miedo a las arañas, encontramos que la variabilidad en términos de tiempo entre sesiones de exposición (i.e., intervalos progresivamente más largos entre sesiones) produjo resultados superiores en el seguimiento en comparación a la exposición agrupada no-variable (Rowe y Craske, 1998; Tsao y Craske, 2000). En muestras con miedo a las arañas o a las alturas, la variabilidad de los estímulos usados durante la exposición llevó a resultados positivos en términos de recuperación espontánea (Rowe y Craske, 1998; Lang y Craske, 2000), aunque en un tercer estudio sobre miedo a la contaminación solo existió una tendencia en este sentido (Kircanski., 2012). La exposición tradicional avanza de un ítem de la jerarquía al siguiente de forma constante, repitiéndose cada uno de los ítems varias veces hasta que la ansiedad disminuye. En cambio, en la exposición variable, la exposición a los ítems de la jerarquía se lleva a cabo en orden aleatorio, sin tener en cuenta los niveles del miedo o su reducción, aunque habitualmente se empieza con el ítem que menos ansiedad produce para evitar el rechazo al tratamiento. Habitualmente llevamos a cabo exposición con estímulos variados, con duraciones variadas, a niveles de intensidad variados, o seleccionamos ítems de una jerarquía de miedo desordenada, en lugar de exponer de forma continuada a una situación hasta que el miedo disminuye, antes de pasar a la siguiente situación. Hay que destacar que esta variabilidad produce niveles más altos de activación fisiológica y ansiedad subjetiva durante la exposición, que no consiguen habituarse (por ejemplo, Kircanski., 2012; Lang y Craske, 2000), y sin embargo produce efectos beneficiosos a largo plazo.

Además, una mayor variabilidad en los niveles de miedo a lo largo de la exposición (i.e., aumentos y disminuciones minuto a minuto en los niveles de miedo) constituye un predictor de resultados positivos en el miedo a la contaminación y ansiedad a hablar en público (Kircanski et al., 2012; Culver et al., 2012). Posiblemente, el estado emocional (i.e., el nivel de miedo) sirve como clave de recuperación, y en las situaciones posteriores a la terapia en que la recuperación es necesaria se pueden dar niveles de miedo variables (Bjork y Bjork, 1992, 2006). Así, la variación en el nivel de miedo a lo largo de la exposición contrarrestará la renovación contextual una vez se haya completado la exposición. La variabilidad en el estado emocional también puede potenciar la saliencia del estímulo fóbico y de este modo potenciar el aprendizaje de asociaciones inhibitorias. Recomendamos ofrecer variabilidad durante las exposiciones, por ejemplo, llevando a cabo duraciones "impredecibles" de las exposiciones a los estímulos fóbicos (con el acuerdo previo de los clientes sobre estos principios generales).

(6) Claves de recuperación. Una opción para favorecer la recuperación del aprendizaje de extinción y contrarrestar la renovación contextual es la inclusión de claves de recuperación (de la asociación EC-no EI) durante los ensayos de extinción, para poder usarlas en otros contextos cuando estos hayan acabado (Brooks y Bouton, 1994; Vansteenwegen et al., 2006; Dibbets y Maes, 2011). Sin embargo, un riesgo de las claves de recuperación es que pueden adquirir un valor inhibitorio y convertirse en señal de seguridad (Dibbets et al. 2008). Las 
claves de recuperación difieren de las señales de seguridad en que recuperan la relación EC-no EI (i.e., actúan como un facilitador), mientras que las señales de seguridad se asocian directamente con la no-ocurrencia del EI. Por ejemplo, el despacho de un terapeuta donde se llevaron a cabo sesiones de exposición previas puede actuar como una clave de recuperación para una nueva exposición, mientras que las benzodiacepinas podrían actuar como señales de seguridad (por ejemplo, en el caso del trastorno de pánico). En un estudio con muestras ansiosas análogas, los efectos de una clave de recuperación (un portapapeles y un bolígrafo) en la renovación contextual fueron muy débiles (Culver et al., 2011), aunque en otro estudio las instrucciones para recuperar mentalmente lo que se aprendió durante la exposición (clave de recuperación instruccional) tuvieron efectos más potentes en la reducción de la renovación contextual (Mystkowski et al., 2006). En el tratamiento de los trastornos de ansiedad, este enfoque implica que las personas lleven encima claves para recordar lo que aprendieron durante la terapia de exposición (por ejemplo, una pulsera), siempre y cuando estas claves no se vuelvan señales de seguridad. También se les pide que recuerden lo que aprendieron durante la terapia de exposición cada vez que se encuentren con las sensaciones o situaciones previamente temidas. Sin embargo, es mejor usar estas estrategias para prevenir recaídas. Utilizar claves de recuperación en los inicios de la terapia, cuando lo importante es la adquisición del aprendizaje de extinción, puede afectar negativamente su progreso, ya que estas claves pueden reducir la expectativa de un evento aversivo (y por tanto mitigar los efectos de violación de expectativas). Además, cualquier clave de recuperación debería utilizarse con moderación, para reducir la posibilidad de convertirse en una señal de seguridad o inhibidor condicionado.

(7) Contextos múltiples. La renovación contextual implica el retorno del miedo a un estímulo fóbico cuando este se encuentra en un contexto (interno o externo) diferente al contexto donde se llevó a cabo la terapia de exposición (Mineka, Mystkowski, Hladek, y Rodriguez, 1999; Mystkowksi et al., 2002; Rodriguez, Craske, Mineka, y Hladek, 1999). Se ha demostrado que los contextos múltiples contrarrestan la renovación contextual en muestras de roedores (por ejemplo, Gunther, Denniston, y Miller, 1998), en estudios de laboratorio con humanos (por ejemplo, Bandarian Balooch y Neumann, 2011; Bandarian Balooch, Neumann, y Boschen, 2012) y en un estudio análogo a la clínica con terapia de exposición (Vansteenwegen et al., 2007). Por otro lado, un estudio de condicionamiento en roedores (Bouton, García-Gutiérrez, Zilkski, y Moody, 2006) y otro en humanos
(Neumann, Lipp, y Cory, 2007) no consiguió demostrar beneficios detectables del uso de contextos múltiples a lo largo de la extinción, lo que sugiere que estos efectos son inestables. La traslación clínica implica llevar a cabo exposiciones interoceptivas, imaginadas y en vivo, en diferentes contextos múltiples; como cuando uno está solo o en sitios poco familiares, o en distintos momentos durante el día o la semana.

(8) Reconsolidación. Recientemente se ha (re)descubierto que la recuperación de recuerdos ya almacenados induce un proceso de reconsolidación (Nader, Schafe, y Le Doux, 2000), debido a que el recuerdo se vuelve a "escribir" en la memoria a largo plazo, requiriendo nuevos procesos neuroquímicos. Así, mediante la recuperación, sería posible modificar los recuerdos durante la ventana temporal de reconsolidación. Monfils, Cowansage, Klann, y LeDoux (2009) utilizaron una estrategia conductual con este propósito e hipotetizaron que la información nueva que se presenta durante la ventana de reconsolidación puede incorporarse al recuerdo y cambiarlo. Por tanto, la extinción durante la ventana de reconsolidación puede debilitar el recuerdo de miedo. Monfils et al. encontraron que una presentación breve del EC, 30 minutos antes de llevar a cabo ensayos sostenidos de extinción, redujo significativamente la recuperación espontánea, la renovación, el restablecimiento, $\mathrm{y}$ la rápida readquisición, en una muestra de roedores. Desde entonces, se ha demostrado el mismo efecto en muestras de humanos sanos (Agren et al., 2012; Schiller et al., 2010). Su implicación clínica consiste en introducir el estímulo fóbico durante un breve periodo, 30 minutos antes de los ensayos de exposición. Sin embargo, al igual que con muchas otras estrategias enumeradas anteriormente, se necesitan más evidencias. Por ejemplo, los hallazgos en relación a la reconsolidación de la pre-exposición no se han replicado en todos los casos (Chan, Leung, Westbrook y McNally, 2010). Además, se produjeron los mismos resultados cuando la breve exposición al EC ocurrió en la ventana previa a la extinción o en una ventana posterior a esta (Baker, McNally, y Richardson, 2013; Ponnusamy et al., 2011), lo que sugiere que los resultados pueden estar más relacionados con favorecer la recuperación del aprendizaje de extinción que con la supresión del aprendizaje de adquisición. Además, en la práctica clínica, la mayoría de los clientes recuperará hasta cierto punto sus recuerdos de miedo cuando se les introduce a las sesiones de tratamiento. La cuestión es qué tipo, grado, o frecuencia de recuperación abre la ventana de reconsolidación y proporciona la oportunidad para actualizar los recuerdos subyacentes (Vervliet, Craske, y Hermans, 2013). 


\section{Estrategia terapéutica para favorecer la regulación inhibitoria}

La neurociencia social ha identificado otra estrategia para favorecer la regulación inhibitoria que consiste en el procesamiento lingüístico o etiquetado de las emociones. El etiquetado de las emociones funcionaría aumentando los procesos asociativos inhibitorios dentro de la extinción, o trabajaría de un modo independiente pero complementario al aprendizaje de extinción. Algunos estudios han mostrado que el procesamiento lingüístico activa una región de la corteza cerebral, la corteza prefrontal ventrolateral derecha, que reduce la actividad de la amígdala, atenuando de este modo las respuestas de ansiedad (Lieberman et al., 2007). Parece que el funcionamiento de las áreas corticales relacionadas con las funciones ejecutivas conlleva la disminución la actividad del sistema límbico. En dos estudios, hemos mostrado que el etiquetado de las emociones mientras los individuos son expuestos a estímulos temidos tiene efectos beneficiosos. Tabibnia, Lieberman, y Craske (2008) mostraron que imágenes repetidas de arañas emparejadas con palabras de valencia negativa e irrelevantes para las imágenes (por ejemplo, "bomba" y "guerra"), produjeron una reducción mayor en la actividad electrodermal antes estas imágenes, una semana más tarde, que imágenes solas. Además, Kircanski et al. (2012) encontraron más beneficios del etiquetado de las emociones en una muestra de personas con fobia a las arañas cuando recibían terapia de exposición. En comparación con pensamientos de reevaluación cognitiva, distracción, y solo exposición, se vio que el etiquetado de las emociones durante la exposición redujo la actividad electrodermal e incrementó las conductas de aproximación, en un seguimiento realizado un mes después en un contexto distinto al de la exposición (Kircanski et al., 2012). Estos datos sugieren que el procesamiento lingüístico en forma de etiquetado, en contraposición a la terapia cognitiva más tradicional que intenta cambiar el contenido de las evaluaciones, puede mejorar los resultados de la exposición. Nosotros preguntamos rutinariamente a los clientes que expresen verbalmente sus respuestas emocionales, sin intentar cambiarlas, durante la exposición.

\section{Estudios de caso}

En la siguiente sección, presentamos ejemplos de implementación de un modelo de exposición basado en el aprendizaje inhibitorio, para una variedad de trastornos de ansiedad. Este conjunto de ejemplos no pretende ser exhaustivo sino más bien ilustrativo.

\section{Trastorno obsesivo-compulsivo}

Roberto, de 43 años de edad, era padre de dos hijos y acudió a la consulta porque tenía imágenes intrusivas relacionadas con hacer daño a su hijo recién nacido. Aunque pensaba que nunca llegaría a herir a su bebé, se sentía totalmente angustiado por estas imágenes. Concretamente, se imaginaba que ahogaba a su hijo mientras este dormía. A menudo buscaba seguridad en su esposa, pidiéndole que le dijera lo buen padre que era. Además, cuando sentía ansiedad debido a estas imágenes, intentaba llevar a su mente la imagen de una interacción positiva con sus hijos. Como resultado de estas imágenes, Roberto disminuyó significativamente el tiempo que pasaba con sus hijos, especialmente cuando se podían quedar a solas, lo que produjo mucha preocupación en su familia. Dejó de acostar a sus hijos por la noche, y se negaba a que sus hijos durmieran con él y su mujer.

En la sesión 1 se habló detenidamente de la naturaleza del aprendizaje asociativo, y de cómo la evitación puede interferir con el nuevo aprendizaje, impidiendo cualquier violación de expectativas. Se quitó importancia a la reducción inmediata del miedo y, en lugar de eso, la discusión se centró en estrategias que, aunque a corto plazo podían producir más angustia, conducirían finalmente a la reducción de miedo.

El terapeuta enfatizó que inicialmente la terapia activaría expectativas de consecuencias negativas -para obtener así una experiencia óptima de aprendizaje con la terapia de exposición- y que esto le podía causar más angustia al principio. El terapeuta insistió en que finalmente se reduciría el miedo como resultado del tratamiento, pero que el mecanismo subyacente a la reducción final sería la continua violación de expectativas. Roberto encontró la expresión "pruébalo" especialmente útil para recordar la lógica que hay detrás de un modelo inhibitorio de la exposición.

Las sesiones 2-5 se centraron en la exposición en vivo. Los ejercicios iniciales de exposición se basaron en pasar tiempo a solas con sus hijos, y sobre todo con su bebé. Se escogieron estos ejercicios porqué se consideraron "medianamente difíciles". Consideramos que empezar por exposiciones de dificultad moderada aumentaba las posibilidades de éxito y facilitaba que el paciente continúe con la terapia. Sin embargo, y en consonancia con el concepto de variabilidad discutido previamente, no avanzamos necesariamente de forma lineal por la jerarquía. Por ejemplo, las exposiciones más difíciles, como poner las manos en el cuello de su hijo mientras este dormía, durante un periodo de tiempo predeterminado, se realizaron al principio de la terapia. Otras exposiciones incluyeron acostar a sus hijos por la noche, 
leer historias de la prensa sobre padres que habían herido a sus hijos y luego jugar con su bebé, o tumbarse al lado de sus hijos mientras dormían la siesta. Roberto se esforzó para llevar a cabo todas las exposiciones solo, ya que la presencia de su esposa actuaba como señal de seguridad reduciendo su expectativa de hacer daño a sus hijos. Las demás señales de seguridad también fueron retiradas gradualmente. Las exposiciones se alargaron para llevar a la mente de forma deliberada las imágenes violentas e intrusivas de ahogar a su hijo, ya que Roberto temía que si llevaba esas imágenes a su mente había más posibilidades de acabar realizando un acto violento. Así, era importante incluir esas imágenes en las sesiones de exposición para maximizar cualquier violación de expectativa. El terapeuta de Roberto trabajó con él para desarrollar un guión detallado de esas imágenes (incluyendo una variedad de elementos sensoriales) para usar durante la exposición.

Aunque a primera vista estas exposiciones son parecidas a las que se llevan a cabo desde los modelos basados en la habituación o los modelos cognitivos, es importante destacar algunas diferencias. Primero, antes de la exposición, Roberto aprendió a describir la consecuencia temida para facilitar la violación de expectativas. Por ejemplo, Roberto explicó que creía, con un $80 \%$ de seguridad, que intentaría ahogar a su hijo mientras dormía, si ponía sus manos en su cuello durante $10 \mathrm{mi}-$ nutos. Se escogió la duración de 10 minutos porqué Roberto dijo que exposiciones más cortas no aumentarían su expectativa de hacer daño a su hijo. Segundo, después de cada ejercicio de exposición dentro de una sesión, Roberto y su terapeuta hablaron detenidamente sobre la no-ocurrencia del evento temido. Esto se hizo con la finalidad de consolidar el aprendizaje de extinción. Preguntas abiertas como "¿qué temías que pasaría como resultado de la exposición?”, “¿qué pasó?”, “¿en qué medida te sorprendió?” y “¿qué aprendiste?” se usaron como parte de una discusión interactiva. Para las prácticas entre sesiones, Roberto tenía hojas de registro en las que antes de la exposición podía apuntar la consecuencia negativa anticipada (por ejemplo, ahogar a su hijo), y luego realizar la consolidación post-exposición. Esto implicaba que Roberto apuntara si la consecuencia temida había ocurrido o no, citando evidencias para aumentar la seguridad de la no-ocurrencia del EI (por ejemplo, “¿cómo sabes que la consecuencia temida no ocurrió?”) y describiendo lo que había aprendido realizando la exposición. Tercero, se pidió a Roberto que continuara con un ensayo de exposición determinado hasta que su expectativa hubiese sido violada, o hubiese alcanzado el objetivo conductual acordado, independientemente de su nivel de angustia. Aunque el miedo suele disminuir a lo largo de los ensayos de exposición, el terapeuta de Roberto explicó que el miedo no necesariamente tenía que disminuir cada vez, ya que cada expectativa incrementada proporcionaba nuevas oportunidades para potenciar el aprendizaje. Las exposiciones a un EC determinado (por ejemplo, tocar el cuello de su hijo mientras dormía), fueron repetidas varias veces a lo largo del tratamiento; sin embargo, se añadieron elementos adicionales ocasionalmente (aumentando la duración de la exposición, añadiendo más estímulos -véase más abajo) para incrementar su expectativa de una consecuencia negativa.

Finalmente, no se utilizó la restructuración cognitiva antes o durante las exposiciones, ya que podía reducir su expectativa de una consecuencia aversiva y mitigar el aprendizaje de extinción. En lugar de eso, el terapeuta de Roberto enfatizó la importancia a la hora de maximizar el aprendizaje de las estrategias que aumentaban la expectativa, y explicó que ciertas estrategias (por ejemplo, conductas de seguridad, o corregir la sobreestimación de la probabilidad) podían afectar negativamente el aprendizaje de extinción. Se reservaron las estrategias "cognitivas" para las discusiones post-exposición para poder facilitar la consolidación del nuevo aprendizaje.

Las sesiones 6-11 continuaron con exposiciones en vivo incorporando algunas estrategias para potenciarlas. Para maximizar el aprendizaje de extinción de un EC determinado, se incluyeron varios estímulos condicionados para "sobrepredecir" la ocurrencia del EI. Esa extinción intensificada se consiguió de varias maneras. Primero, después de llevar a cabo varias exposiciones a estímulos por separado, dos estímulos fueron combinados en un compuesto. Por ejemplo, inicialmente Roberto llevaba a cabo exposiciones por separado a: a) poner la mano en el cuello de su hijo mientras este dormía, y b) llevar a su mente imágenes intrusivas. Luego, estas fueron combinadas en una única sesión de exposición. Segundo, los estímulos que fueron extinguidos por separado fueron presentados ocasionalmente durante un nuevo ensayo de exposición. Esto aumenta la expectativa para el nuevo EC mientras mantiene a la vez su saliencia. Por ejemplo, antes de bañar a su bebé por primera vez, Roberto combinó esta exposición con leer historias en la prensa sobre padres que habían hecho daño a sus hijos (exposición que ya había hecho previamente).

Antes de finalizar, el terapeuta de Roberto discutió la naturaleza dependiente de contexto del aprendizaje de extinción, y sugirió varias estrategias de prevención de recaídas. Específicamente, Roberto trabajó para "recuperar mentalmente" contextos de extinción previos, imaginando en detalle una sesión de exposición que había funcionado (i.e., se había violado su expectativa). Esto 
Tabla 1. Ejemplos de ejercicios de exposición en el trastorno obsesivo-compulsivo

\section{Sesión 3}

Antes de la exposición

Objetivo:

¿Qué es lo que más te preocupa que pueda ocurrir?

En una escala del $0-100$, indica su grado de probabili- $80 \%$.

dad:

\section{Después de la exposición}

¿Hiciste lo que más te preocupaba que ocurriera? Sí o No. No

¿Cómo lo sabes?

Mi mano nunca apretó su cuello.

¿Qué aprendiste?

Puedo estar solo con mi hijo, mientras él duerme, y no herirlo.
Pon la mano en el cuello de tu hijo mientras duerme (4 veces durante la semana).

Voy a estrangularlo.

No.

\section{Sesión 4}

Antes de la exposición

Objetivo:

¿Qué es lo que más te preocupa que pueda ocurrir?

En una escala del 0-100, indica su grado de probabili- $\quad 70 \%$ dad:

\section{Después de la exposición}

¿Hiciste lo que más te preocupaba que ocurriera? Sí o No No

¿Cómo lo sabes?

¿Qué aprendiste?

\section{Sesión 6}

Antes de la exposición

Objetivo:

¿Qué es lo que más te preocupa que pueda ocurrir?

En una escala del 0-100, indica su grado de probabili- $\quad 90 \%$

dad:

Después de la exposición

¿Hiciste lo que más te preocupaba que ocurriera? Sí o No No

¿Cómo lo sabes?

¿Qué aprendiste?
Leer historias en la prensa sobre padres que hirieron a sus hijos, durante 15 min., y luego jugar con los niños durante $10 \mathrm{~min}$. (3 veces durante la semana).

Voy a hacer daño a mis hijos.

Nunca hice daño a mis hijos, incluso cuando estaba solo con ellos.

Leer historias sobre otras personas que hicieron daño a sus hijos no significa que yo lo haré. 
lo practicó en varios ensayos de exposición durante su última semana de terapia, pero se le avisó que no lo hiciera demasiado a menudo, y que no lo usara como señal de seguridad. En la Tabla 1 se muestran ejemplos de varios ensayos de exposición.

\section{Trastorno por estrés postraumático}

Hacía un año que Julia había sobrevivido a un ataque sexual, pero seguía sintiéndose ansiosa por imágenes del suceso y la evitación de muchas situaciones. A menudo evitaba estar a solas, prefiriendo ir acompañada de uno o varios amigos cuando salía de casa. Explicó que evitaba cualquier tipo de interacción social donde los otros podían estar bebiendo alcohol, ya que temía que el alcohol aumentaría las probabilidades de que un posible atacante actuara de forma violenta. Además, siempre llevaba encima un spray de defensa para protegerse de posibles ataques. Julia contó que deseaba tener una relación sentimental, pero que tenía mucho miedo del contacto interpersonal con una posible pareja.

En la sesión 1 se habló detenidamente de la naturaleza del aprendizaje asociativo, y de cómo la evitación y las conductas de seguridad impiden la violación de expectativas e interfieren con la exposición. Además, Julia y su terapeuta hicieron una lista de las situaciones que evitaba y de las consecuencias temidas asociadas a estas situaciones. A pesar de que la jerarquía contenía valoraciones de ansiedad elevadas, y en consonancia con el concepto de variabilidad discutido previamente, las exposiciones no se realizaron linealmente de menos a más ansiógenas.

Las sesiones 2-4 se dedicaron a exposiciones en vivo centradas en la violación de expectativas, mientras se reducía el uso de las conductas de seguridad por parte de Julia. Las exposiciones consistían en ir sola a reuniones sociales (sobre todo en situaciones en las que los presentes podían estar tomando alcohol), salir de casa sin el spray, y empezar a salir con chicos. En consonancia con un modelo inhibitorio, antes de empezar las exposiciones se pidió a Júlia que expresara la consecuencia negativa temida, y que se fijara en la no-ocurrencia del EI después de cada exposición.

Las sesiones 5-12 continuaron con la exposición en vivo e incorporaron además exposiciones imaginadas de su trauma. Julia expresó algunas preocupaciones relacionadas con la realización de la exposición imaginada, como ser incapaz de tolerar la ansiedad asociada a la exposición, y estar demasiado afectada para realizar otras actividades a lo largo del día. Julia y su terapeuta trabajaron conjuntamente para clarificar y definir operativamente estas expectativas, para luego "someterlas a prue- ba". Por ejemplo, su incapacidad percibida para tolerar la ansiedad se relacionaba con la preocupación de que el estrés de la exposición le causaría un "colapso mental" y le haría "volverse loca". Para abordar sus preocupaciones relacionadas con la incapacidad de llevar a cabo otras tareas, se pidió a Julia que hiciera otras actividades (por ejemplo, preparar la cena, o terminar una tarea del trabajo) justo después de las exposiciones imaginadas. El terapeuta también animó a Julia a que etiquetara su experiencia emocional antes y durante las exposiciones imaginadas, para potenciar el aprendizaje inhibitorio (i.e., etiquetado de las emociones).

Julia expresó que sentía mucha vergüenza en relación a su trauma, y expresó que temía que los otros la juzgaran por las acciones que había emprendido, o no, después del ataque. Las exposiciones iniciales con su terapeuta le dieron la oportunidad de violar esta expectativa, ya que el terapeuta no juzgó a Julia por lo que le había contado. Se animó a Julia a que compartiera sus preocupaciones y los detalles de su historia con amigos íntimos, para así proporcionar una violación adicional de esta asociación condicionada.

Aparte de estas preocupaciones, Julia expresó que las imágenes traumáticas eran especialmente aversivas, debido a su naturaleza muy vívida. Su terapeuta le explicó cómo la exposición repetida le permitiría diferenciar entre la experiencia del recuerdo y el evento en sí mismo (discriminación de estímulos). De hecho, la investigación sugiere que la exposición repetida conduce a un mejor aprendizaje perceptivo o discriminación de estímulos (Tsodyks y Gilbert, 2004). Además, la exposición repetida a los elementos aversivos del recuerdo puede finalmente reducir su saliencia, posibilitando que la saliencia de señales contextuales no aversivas se ponga en primer plano. La adición de estas señales contextuales (por ejemplo, la seguridad de la oficina del terapeuta) puede facilitar los intentos de discriminación. Aunque no está directamente relacionada con los modelos de inhibición discutidos previamente, la discriminación de estímulos es un concepto importante en las teorías del aprendizaje asociativo, que puede tener relevancia para las imágenes intrusivas muy vívidas. .

Este enfoque se diferenciaba de un modelo basado en la habituación porqué se centraba en los aspectos de violación de las expectativas y la discriminación de estímulos, utilizando etiquetado de las emociones, y ligando la finalización de las exposiciones a objetivos conductuales, y no al nivel de miedo. Además, este enfoque difería de los modelos cognitivos en la medida en que evitaba la inclusión de la restructuración cognitiva antes o durante la exposición, y utilizaba procesos de exposición y ex- 
Tabla 2. Ejemplos de ejercicios de exposición en el trastorno por estrés postraumático

\section{Sesión 3}

Antes de la exposición

Objetivo:

¿Qué es lo que más te preocupa que pueda ocurrir?

En una escala del 0-100, indica su grado de probabili- $\quad 60 \%$

dad:

\section{Después de la exposición}

¿Pasó lo que más te preocupaba? Sí o No

¿Cómo lo sabes?

¿Qué aprendiste?

No.
Ir a un bar durante 30 min., sin el móvil o espray

Se acercará un hombre borracho y me empezará a tocar.

Aunque algunos hombres se acercaron, todos fueron respetuosos y ninguno actuó agresivamente.

Puedo ir a eventos sociales donde la gente bebe y estar segura.

\section{Sesión 5 (con el terapeuta)}

\section{Antes de la exposición}

Objetivo:

¿Qué es lo que más te preocupa que pueda ocurrir?

En una escala del 0-100, indica su grado de probabilidad:

Después de la exposición

¿Pasó lo que más te preocupaba? Sí o No

¿Cómo lo sabes?

¿Qué aprendiste?

\section{Sesión 7 (con el terapeuta)}

\section{Antes de la exposición}

Objetivo:

¿Qué es lo que más te preocupa que pueda ocurrir?

En una escala del 0-100, indica su grado de probabili- $\quad 70 \%$ dad:

Después de la exposición

¿Pasó lo que más te preocupaba? Sí o No

¿Cómo lo sabes?

¿Qué aprendiste?
Llevar a cabo exposición imaginada durante 20 min (escuchar la grabación 4 veces durante la semana).

Seré incapaz de aguantar la angustia y saldré corriendo de la habitación.

$80 \%$

No.

Estuve en la habitación todo el rato.

Puedo empezar a afrontar estos recuerdos espantosos.
Llevar a cabo exposición imaginada durante $20 \mathrm{~min}$., luego responder a e-mails durante $10 \mathrm{~min}$.

Seré incapaz de responder a los correos con eficacia.

No.

Releí los e-mails y tenían sentido. La gente respondió a los e-mails como si los hubiera entendido.

Puedo hacer cosas después de afrontar el recuerdo. tinción, en lugar de intervenciones cognitivas, para tratar reacciones condicionadas adicionales como la vergüenza. En la Tabla 2 se muestran ejemplos de varios ensayos de exposición.

\section{Fobia social}

Leandro es un hombre de 40 años que al inicio del tratamiento tenía miedo al rechazo social y a la humilla- 
ción. Después de un aumento de los síntomas de ansiedad social, aproximadamente un año antes, Leandro se negó a solicitar puestos de trabajo o socializar con los amigos de su mujer. El principal motivo para buscar tratamiento fue intentar arreglar su matrimonio, que se había visto perjudicado por su evitación social.

La sesión 1 consistió en psicoeducación y planificación del tratamiento. El terapeuta discutió la prevalencia, los orígenes, y la psicopatología de la fobia social, y los fundamentos de las psicoterapias basadas en la exposición (por ejemplo, los principios del condicionamiento asociativo). Fue importante proporcionar una explicación franca y detallada de las responsabilidades que tendría Leandro durante la terapia de exposición, para poder evaluar su predisposición a seguir un programa que incluía "tareas para casa".

Uno de los principios que Leandro siguió desde la sesión inicial fue la aproximación al tratamiento del "científico personal", reflejando el énfasis que se da al empirismo en esta terapia de exposición. Cada ejercicio de exposición se diseñó para evaluar una hipótesis (típicamente, "el EC predice al EI"). Además, el terapeuta explicó que algunas exposiciones implicarían niveles sostenidos de ansiedad, y que el objetivo inmediato de la exposición no era la reducción de la ansiedad.

Se dedicaron las sesiones 2-5 a hacer un inventario de situaciones temidas, confeccionando conjuntamente los ejercicios de exposición correspondientes, y llevando a cabo exposiciones dentro y fuera de las sesiones. Durante el diseño de los ejercicios de exposición, se registró el nivel de ansiedad anticipada por Leandro, pero estas predicciones no se usaron para determinar el orden de los ejercicios, como se suele hacer en los modelos basados en la habituación. En lugar de eso, el énfasis se puso en la comprobación de hipótesis, o aprendizaje, que era necesario llevar a cabo en cada escenario. El orden de los ejercicios de exposición se determinó en función de lo que Leandro consideraba como la experiencia de aprendizaje más apremiante en ese momento del tratamiento. Por ejemplo, al inicio del tratamiento, Leandro estaba más preocupado en comprobar que los amigos de su esposa no lo humillarían, e inicialmente las exposiciones se centraron en atender eventos sociales con su esposa, a pesar de que estos ejercicios fueron valorados como más ansiógenos que otras de las situaciones evitadas (por ejemplo, el trato con dependientes de las tiendas).

El ejercicio de exposición típico en este caso fue bastante estructurado e implicaba varios pasos. Primero, el terapeuta establecía lo que Leandro esperaba que ocurriera en las situaciones sociales que percibía como amenazantes. Esta predicción fue apuntada en una hoja bajo la etiqueta de hipótesis. Una de sus hipótesis era que si expresaba una opinión a un compañero de trabajo sería tratado de incompetente, lo cual se manifestaría en miradas burlonas y evitación. (A lo largo de los ejercicios, Leandro aprendió a formular sus hipótesis en términos conductuales específicos, dado que las hipótesis vagas eran demasiado difíciles de apoyar o rechazar de un modo objetivo). Segundo, Leandro llevó a cabo la conducta social y comprobó el resultado. Al igual que un buen científico, Leandro registró en una hoja las respuestas de sus compañeros de trabajo, usando un lenguaje objetivo. Trató la descripción conductual de la respuesta como el resultado de la comprobación de hipótesis, o evidencias. Tercero, Leandro y su terapeuta contrastaron la hipótesis con las evidencias. El terapeuta lo guío en este proceso de un modo socrático haciéndole preguntas como "¿son consistentes las evidencias con lo que habías predicho?" o " $¿$ aprendiste algo de las respuestas de tus compañeros de trabajo hacia ti?" A medida que avanzaba la terapia, Leandro hizo esta consolidación por su cuenta, pudiendo consultar unas preguntas estándar sobre la asociación EC-EI cuando fue necesario.

Aunque el proceso de consolidación se puede considerar como una forma de terapia cognitiva, hay varios puntos en los que el tratamiento para Leandro se distingue de las terapias cognitivo-conductuales tradicionales para la fobia social. Primero, no se implementó la reestructuración cognitiva antes de las exposiciones para reducir la ansiedad anticipatoria o prepararlo para los ensayos de exposición. La lógica detrás de esta decisión fue mantener la expectativa del EI antes de la exposición de modo que el ensayo pudiera producir una violación máxima de la expectativa. Las preguntas "itiene algún sentido estar preocupado por la fiesta del próximo fin de semana? ¿Qué pasó en las últimas fiestas en las que has estado?" se considerarían una reestructuración pre-exposición útil en algunas terapias, pero en realidad limitarían el aprendizaje inhibitorio que sigue a la violación de expectativas. Segundo, no se aplicó la reestructuración cognitiva en medio de las exposiciones. En una terapia cognitivo-conductual tradicional, se podría haber pedido a Leandro que se fijara con los elementos no-amenazantes o positivos de una situación social durante un ejercicio de exposición como una forma de demostrar que no todos los aspectos del evento eran negativos. Sin embargo, esa estrategia también podría haber distraído a Leandro de la relación EC-no EI, y por tanto disminuir en último término el aprendizaje inhibitorio.

Varias características de nuestros ensayos de exposición los diferenciaban de un enfoque basado en la habituación. La principal diferencia fue el énfasis en la vio- 
lación de expectativas, más que en los niveles de miedo, en las etapas de diseño y consolidación. El rigor con que el terapeuta generó una hipótesis objetiva, y orientada a la conducta, para cada ejercicio, y el cuestionamiento socrático en relación a las discrepancias entre hipótesis y evidencias, se derivaron de la importancia de la violación de expectativas en el modelo inhibitorio del aprendizaje, y es consistente con el "modelo de comprobación conductual" de la exposición dentro de la terapia cognitivo-conductual. Además, las exposiciones de Leandro fueron diseñadas, en cierta medida, para incrementar la variabilidad del miedo inducido durante los ejercicios, y a lo largo del tratamiento, implicando a veces miedo sostenido. En ese sentido, se distinguían de los enfoques de la terapia de exposición basados en la habituación y los ensayos conductuales. Por ejemplo, no hubo relación lineal entre el número de ejercicios de exposición que llevó a cabo y sus valoraciones de miedo iniciales o finales. Leandro alcanzó niveles máximos de miedo durante algunas de las primeras exposiciones y durante algunas de las últimas. Además, expresó niveles elevados de miedo durante todo el transcurso de algunas exposiciones. Dado que la duración de las exposiciones no depende del miedo subjetivo, muchas acabaron sin una disminución significativa en las valoraciones de miedo.

En las sesiones 6-12, el terapeuta ayudó a Leandro a diseñar exposiciones "aumentadas" para potenciar el aprendizaje inhibitorio. Primero, se identificaron y eliminaron conductas de seguridad sutiles, relacionadas con la forma en que Leandro interactuaba en las situaciones sociales. Por ejemplo, se disuadió a Leandro de jugar con las manos, llevar auriculares, o llevar una revista para leer, como formas de distraerse durante los ejercicios de exposición. A medida que se eliminaron las conductas de seguridad, Leandro prestó más atención a las asociaciones (o la ausencia de éstas) entre el EC (entorno social) y el EI (cambios específicos en las expresiones faciales y la mirada de sus interlocutores). Este cambio en el foco atencional permitió una violación máxima de las expectativas EC-EI (i.e., hipótesis). Segundo, y en la misma línea, el terapeuta de Leandro trabajó con él para contrarrestar su tendencia a revivir imaginariamente, después de las exposiciones, aspectos negativos de las interacciones sociales. Este "procesamiento post evento" podría haber interrumpido el aprendizaje de extinción, en la medida en que interfería con la consciencia de la no-ocurrencia del EI. Mediante la refocalización de su atención en indicadores conductuales concretos de la no-ocurrencia del rechazo, Leandro supo discernir mejor la relación no-contingente entre las señales sociales y las consecuencias aversivas.
Tercero, Leandro llevó a cabo exposiciones que implicaban una probabilidad muy alta de feedback social negativo. Realizó algunos "ataques de vergüenza", en los que actuó deliberadamente de un modo que muy probablemente podía provocar miradas de desconcierto o desaprobación. Expresado en términos de un modelo de aprendizaje inhibitorio, este procedimiento aumentó las probabilidades de exposición al EI (extinción reforzada ocasionalmente). Un ejemplo de ataque de vergüenza fue pasar una sesión de la terapia en un ascensor gritando el número de cada planta cuando la gente entraba y salía, fijándose especialmente en las reacciones faciales y verbales de los demás. La Tabla 3 presenta otros ejemplos de ensayos de exposición.

\section{Fobia especifica}

Sara era una chica de 25 años que estaba buscando tratamiento para su fobia a los perros. Temía a los perros, sobre todo a los grandes, desde que a los 10 años de edad vio como un perro atacó a su hermana mayor. La fobia era problemática porque Sara se negaba a visitar algunos de sus amigos más cercanos, porque tenían mascotas en casa, una decisión que produjo tensión en sus relaciones sociales. Además, recientemente había dejado de jugar a futbol -una actividad de ocio muy importante para ella- porque a menudo sus compañeras de equipo llevaban sus perros a los entrenamientos y partidos.

La sesión 1 incluyó una evaluación detallada de las conductas de evitación situacional y una discusión de cómo el modelo de terapia de exposición podía ayudar a Sara a recuperar las actividades sociales y de ocio que se habían visto afectadas por la fobia a los perros. El terapeuta explicó los paralelismos entre los ejercicios de exposición sistemática y la comprobación de hipótesis en investigación científica. Sara aceptó que el programa de exposición implicara estar de nuevo en contacto con situaciones que temía y evitaba, y que el objetivo era experimentar esas situaciones de un modo que hiciera posible nuevos aprendizajes, en lugar de conseguir una reducción inmediata del miedo. En la sesión 1 también se definieron cuidadosamente los objetivos conductuales del tratamiento. El terapeuta explicó que la terapia podía finalizar en cualquier momento, una vez se hubieran alcanzado los objetivos, pero que se recomendaban 6-12 sesiones para poder explicar y ensayar los principios básicos de la exposición, así como las estrategias específicas de aprendizaje inhibitorio.

Las sesiones 2-5 se destinaron a la práctica repetida de exposición en vivo. Se enseñó a Sara a usar una hoja de registro para apuntar las situaciones temidas y lo que ella creía que ocurriría en cada situación. Para uno de los 
Tabla 3. Ejemplos de ejercicios de exposición en fobia social

\section{Sesión 3}

$\underline{\text { Antes de la exposición }}$

Objetivo:

¿Qué es lo que más te preocupa que pueda ocurrir?

En una escala del 0-100, indica su grado de probabili- $\quad 95 \%$

dad:

\section{Después de la exposición}

¿Pasó lo que más te preocupaba? Sí o No

¿Cómo lo sabes?

¿Qué aprendiste?

\section{Sesión 4}

\section{Antes de la exposición}

Objetivo:

¿Qué es lo que más te preocupa que pueda ocurrir?

En una escala del $0-100$, indica su grado de probabili- $\quad 80 \%$ dad:

\section{Después de la exposición}

¿Pasó lo que más te preocupaba? Sí o No

¿Cómo lo sabes?

¿Qué aprendiste?
Expresar una opinión el trabajo (4 veces durante la semana).

Mi compañero me mirará despectivamente y se irá sin responder.

No.

Mi compañero respondió inmediatamente, estuvo de acuerdo con mi opinión, y seguimos hablando.

Los compañeros de trabajo no siempre están en contra de mis opiniones.

\section{Sesión 9}

\section{Antes de la exposición}

Objetivo:

¿Qué es lo que más te preocupa que pueda ocurrir?

En una escala del 0-100, indica su grado de probabili- $\quad 90 \%$ dad:

\section{Después de la exposición}

¿Pasó lo que más te preocupaba? Sí o No

¿Cómo lo sabes?

¿Qué aprendiste?

No.
Predecir resultados de competiciones deportivas en el gimnasio o en un bar (sin alcohol).

La gente me mirará con desprecio (cejas fruncidas y ojos entrecerrados) y se irá.

No.

La gente respondió con sus propias predicciones. No parecían expresar desprecio.

Los desconocidos no necesariamente me van a ignorar.
Ir en el ascensor del centro comercial del barrio durante $30 \mathrm{~min}$. gritando el número de cada planta (4 veces a lo largo de una semana).

La gente me mirará enfadada, me sentiré humillado, me pondré a llorar y dejaré el ascensor.

Recibí más miradas de desconcierto que de enfado. Me sentí humillado, pero no lloré y fui capaz de seguir dentro del ascensor durante $30 \mathrm{~min}$.

Aunque me sentí humillado, es solo un estado temporal, y al fin y al cabo puedo tolerarlo. 
ejercicios, Sara escribió que evitaba "estar en la línea de banda durante un partido de futbol" porqué predecía que "me morderá uno de los perros de mis compañeros de equipo." El terapeuta buscaba opciones para ayudar a Sara a concretar más sus hipótesis ya que, al igual que en la investigación científica, las hipótesis deben ser suficientemente específicas como para ser refutables. Se indicó a Sara que detallara las características de la línea de banda del campo que predijeran de manera máxima una mordedura de perro: "Estar de pie en la línea de banda, a 10 metros de un perro, por más de 10 minutos durante un partido de fútbol." Luego, se encargó a Sara que se aproximara a esa situación durante un partido de fútbol y apuntara el resultado en su hoja de registro. El terapeuta incluso le desafió a mantenerse 5 minutos más en la línea de banda para llevar a cabo un test especialmente riguroso de la hipótesis que el perro la mordería. Durante la siguiente sesión, el terapeuta le enseñó a comparar metódicamente los resultados de la comprobación de hipótesis (i.e., la evidencia) con su hipótesis. Sara explicó que la evidencia que había experimentado refutaba su hipótesis (i.e., no hubo ninguna mordedura de perro), y trabajó con el terapeuta para generar una caracterización revisada y más plausible de la asociación EC-EI (por ejemplo, "puedo estar cerca de un perro durante todo el partido sin que me muerda"). Fue muy importante explicar que esa exposición, y otras como esa, no implican mantenerse en la situación evitada hasta que el miedo disminuye. En lugar de eso, las exposiciones se orientaron a la violación de expectativas; eso es, la finalización del ejercicio de exposición venía determinada por las especificaciones de la hipótesis temporal (la mordedura del perro ocurrirá durante el intervalo 10 minutos). De hecho, Sara explicó que su miedo no había disminuido substancialmente al final de la exposición de la línea de banda.

Las sesiones 6-12 "aumentaban" las exposiciones con estrategias trazadas desde la investigación del aprendizaje inhibitorio. El principio de contextos múltiples fue especialmente importante: es decir, los contextos de exposición fueron variados deliberadamente para favorecer la recuperación y generalización del aprendizaje inhibitorio. Por ejemplo, se diseñaron las exposiciones para que Sara se acercara a perros de varios tamaños y en múltiples contextos, especialmente en situaciones que posiblemente serían más importantes para ella una vez finalizada la terapia (por ejemplo, en la casa de un amigo o en el campo de fútbol). Sara también realizó ejercicios de exposición por sí misma (sin la presencia de amigos, en los ejercicios entre sesiones), ya que contar con la presencia de los demás para amansar a un perro agresivo podría haber servido de señal de seguridad e impedido la violación total de su expectativa de que un perro le atacara. Dado que se valoró la variabilidad en los contextos de exposición, más que repetir la exposición en un único contexto hasta que el miedo disminuyera, los niveles de miedo no fueron uniformemente bajos a medida que la terapia avanzaba.

Las exposiciones también variaron en relación a contextos internos, principalmente los niveles de miedo que Sara experimentaba durante el ejercicio. A pesar de que las exposiciones empezaron con perros pequeños para reducir la probabilidad de que Sara se negara a hacer el tratamiento, el terapeuta no ordenó los ejercicios de exposición de un modo gradual y progresivo, siguiendo una jerarquía lineal o "escalera" en función del grado de miedo. Como consecuencia, hubo una variabilidad importante en el miedo indicado por Sara a lo largo de los ensayos de exposición, y algunos ensayos terminaron después de haber alcanzado el objetivo del ejercicio y/o haber violado la expectativa- cuando el miedo aún era relativamente alto. En la Tabla 4 se muestran ejemplos de ensayos de exposición concretos.

\section{Trastorno de pánico}

Carlos era un hombre de 43 años que tenía una empresa de construcción. Aunque no había tenido problemas de salud importantes a lo largo de su vida, experimentó su primer ataque de pánico inesperado dos años antes de acudir a la consulta. Al principio, esos ataques de pánico ocurrían una vez cada dos meses. Sin embargo, en los últimos seis meses la frecuencia de sus ataques había aumentado hasta aproximadamente uno por semana. Carlos estaba muy preocupado por si tenía más ataques de pánico, y por lo que los ataques significaban por su salud. A pesar de que había visitado a varios médicos, y que las pruebas habían salido favorables, estaba convencido que los ataques de pánico le causarían un infarto o un ataque al corazón. Concretamente, temía que las sensaciones interoceptivas (mareo, dificultades en la respiración y palpitaciones) estuvieran relacionadas con una enfermedad o pudieran empeorar su salud. Un médico le recetó benzodiacepinas para disminuir la ansiedad, y él se las tomaba según creía conveniente. Carlos había dejado de hacer ejercicio, raramente hacía trabajos físicos, y evitaba jugar con sus hijos a cosas que implicaran un esfuerzo, porque creía que esas actividades le causarían un ataque al corazón. La esposa de Carlos lo acompañaba a las obras de construcción -donde el polvo podía dificultar la respiración- para que él estuviera más tranquilo, y jugaba con los niños para que él pudiera descansar. Los ataques de pánico causaron mucha angustia a Carlos y le afectaron completamente su 
Tabla 4. Ejemplos de ejercicios de exposición en fobia específica

\section{Sesión 4}

Antes de la exposición

Objetivo:

En un partido de fútbol, estar en la línea de banda, a 10 metros de un perro, durante $15 \mathrm{~min}$.

¿Qué es lo que más te preocupa que pueda ocurrir?

Antes que pasen los 10 min., un perro me morderá.

En una escala del 0-100, indica su grado de probabili- $\quad 99 \%$

dad:

\section{Después de la exposición}

¿Pasó lo que más te preocupaba? Sí o No

No.

¿Cómo lo sabes?

Ningún perro se me acercó.

¿Qué aprendiste?

Probablemente, podría estar en la línea de banda durante todo el partido sin que me muerda un perro.

\section{Sesión 5}

Antes de la exposición

Objetivo:

¿Qué es lo que más te preocupa que pueda ocurrir?

En una escala del 0-100, indica su grado de probabili- $\quad 85 \%$

dad:

\section{Después de la exposición}

¿Pasó lo que más te preocupaba? Sí o No

¿Cómo lo sabes?

¿Qué aprendiste?

No.
Acariciar el perro de una amiga durante $30 \mathrm{~min}$.

El perro me morderá.

El perro nunca me mordió y parecía disfrutar de mi compañía (lamió mi mano y estuvo en mi falda).

Algunos perros no muerden cuando los estás acariciando.

\section{Sesión 10}

\section{Antes de la exposición}

Objetivo:

¿Qué es lo que más te preocupa que pueda ocurrir?

En una escala del 0-100, indica su grado de probabili- $\quad 70 \%$

dad:

\section{Después de la exposición}

¿Pasó lo que más te preocupaba? Sí o No

¿Cómo lo sabes?

¿Qué aprendiste?

No.
Mirar un partido de fútbol entero (90 min.) estando sentada en el suelo, agarrando dos perros por la correa (no pertenecen a mis compañeras de equipo).

Un perro me morderá y no estaré en una posición que me permita defenderme o correr.

Los perros no hicieron ningún movimiento amenazador y parecieron acostumbrarse a mí al cabo de un rato.

Puedo estar en una posición relativamente vulnerable cerca de perros. 
vida cotidiana, lo que le motivó a buscar tratamiento psicológico.

En la sesión 1 se habló del aprendizaje asociativo, de cómo la evitación impide el aprendizaje de extinción, y de la importancia de las exposiciones para conseguir una reducción del miedo (final, no inmediata). El terapeuta de Carlos incorporó tres estrategias de potenciación de la extinción en el tratamiento: violación de las expectativas, extinción intensificada, y retirada de las señales de seguridad.

Las sesiones 2-7 se centraron principalmente en la exposición interoceptiva, mediante la inducción de mareo, dificultades en la respiración, y palpitaciones. Para producir mareo, Carlos giraba en círculos. Dado que Carlos creía que había un $85 \%$ de probabilidades de tener un infarto o un ataque al corazón cuando se sentía mareado por 30 segundos, llevó a cabo una exposición con una duración más larga: 60 segundos. Esto se hizo para maximizar la violación de expectativas de Carlos. Para inducir dificultades en la respiración, Carlos respiraba a través de una cañita, visitaba obras donde había mucho polvo, o hacía ejercicio. Estas exposiciones también se diseñaron para que Carlos aguantara hasta el punto en que creía que tendría un infarto o un ataque al corazón. Finalmente, Carlos tomaba cafeína para inducir palpitaciones. Tomó más cafeína que la cantidad que creía que le produciría un ataque al corazón o un infarto. Se dedicaron dos sesiones a cada uno de estos síntomas interoceptivos.

Desde la sesión 4, las exposiciones incluían la retirada gradual de señales de seguridad. Carlos empezó a acudir a la terapia sin que su esposa esperara fuera de la habitación y también se le pidió que no volviera a llevar benzodiacepinas a las sesiones. A partir de la sesión 7, Carlos fue capaz de llevar a cabo exposiciones entre sesiones sin la presencia de las señales de seguridad.

Las sesiones 8-14 se centraron en la extinción intensificada, que implicaba combinar los distintos estímulos temidos, "extinguidos" previamente por separado, para potenciar el aprendizaje de extinción. Para Carlos, esto significaba combinar falta de aliento con palpitaciones. Estas exposiciones implicaron tomar cafeína antes de hacer ejercicio o jugar con sus hijos. Luego, el terapeuta diseñó exposiciones para añadir el mareo (por ejemplo, girar en círculos antes de hacer ejercicio o jugar con sus hijos). Esta combinación hizo que Carlos pensara que había un $99 \%$ de probabilidades de tener un infarto o un ataque al corazón. Así, los tres síntomas interoceptivos temidos por Carlos fueron incluidos en una exposición para maximizar la violación de expectativas.

Las exposiciones llevadas a cabo se diferenciaban de los modelos basados en la habituación en una cuestión importante. Aunque Carlos indicara su nivel de miedo antes y después de cada exposición, no se dio especial importancia a la reducción del miedo durante las exposiciones. En lugar de eso, el terapeuta de Carlos proponía estrategias que incrementaban continuamente la expectativa de miedo para favorecer el aprendizaje de extinción.

Además, este enfoque se diferenciaba de los modelos cognitivos que enfatizan la revaluación de interpretaciones catastróficas y la atención a posibles señales de seguridad antes o durante la exposición (Clark y Beck, 2010). Por ejemplo, en las intervenciones cognitivo-conductuales tradicionales para el trastorno de pánico, se le puede pedir a un cliente que valore la probabilidad de que un elevado ritmo cardíaco le acabe produciendo un ataque al corazón: "¿Cuantas veces has tenido un ritmo cardíaco elevado? ¿Cuantas veces has tenido un ataque al corazón? ¿Qué pasó la última vez que hiciste ejercicio físico?" Reducir interpretaciones catastróficas y dirigir la atención a posibles señales de seguridad en el entorno antes de la terapia de exposición puede afectar de forma inadvertida el aprendizaje de extinción, reduciendo la expectativa y disminuyendo la atención a estímulos condicionados excitatorios. Sin embargo, esta revaluación cognitiva se puede hacer después de la exposición para consolidar el aprendizaje que se ha producido.

En la Tabla 5 se presentan ejemplos de ensayos de exposición.

\section{Sumario}

La traslación del aprendizaje de extinción a la terapia de exposición para los trastornos de miedo y ansiedad implica la adquisición inicial, la consolidación, y la posterior recuperación de nuevos aprendizajes. Aunque el objeto de la exposición puede variar dependiendo del trastorno que se está tratando, la terapia de exposición contendrá en cualquiera de los casos los siguientes elementos. Primero, un objetivo específico de la terapia de exposición: El terapeuta y el cliente deciden conjuntamente el objetivo específico de la práctica, definiéndolo en términos de duración o de objetivos conductuales específicos y medibles. En segundo lugar, viene la consecuencia negativa anticipada: El terapeuta pregunta al cliente cual es la consecuencia particularmente temida de participar en la tarea. Luego se diseñan las exposiciones y se llevan a cabo hasta que una consecuencia anticipada o expectativa es violada. En tercer lugar hay el reconocimiento y la consolidación de la no-ocurrencia del evento anticipado: Después de haber terminado una práctica de exposición los terapeutas ayudan a los clientes a reflexionar sobre la no-ocurrencia del evento temi- 
Tabla 5. Ejemplos de ejercicios de exposición en trastorno de pánico

\section{Sesión 2}

Antes de la exposición

Objetivo:

¿Qué es lo que más te preocupa que pueda ocurrir?

En una escala del 0-100, indica su grado de probabili- $\quad 85 \%$

dad:

\section{Después de la exposición}

¿Pasó lo que más te preocupaba? Sí o No

¿Cómo lo sabes?

¿Qué aprendiste?

No.
Girar en círculos durante 60 segundos.

Tendré un infarto.

Estuve consciente y no noté ningún dolor.

Sentirse mareado no necesariamente significa que tendré un infarto.

\section{Sesión 8}

Antes de la exposición

Objetivo:

Ir a correr durante $15 \mathrm{~min}$.

¿Qué es lo que más te preocupa que pueda ocurrir?

Estar sin aliento y tener el corazón acelerado me producirá un ataque al corazón.

En una escala del 0-100, indica su grado de probabili- $\quad 75 \%$

dad:

\section{Después de la exposición}

¿Pasó lo que más te preocupaba? Sí o No

No.

¿Cómo lo sabes?

Mi corazón no se paró.

¿Qué aprendiste?

Aunque esté sin aliento y tenga el corazón acelerado, no necesariamente tendré un ataque al corazón, incluso si me pasa a la vez.

\section{Sesión 14}

\section{Antes de la exposición}

Objetivo:

¿Qué es lo que más te preocupa que pueda ocurrir?

Girar en círculos durante 60 segundos e ir a correr durante 15 min. sin mis pastillas o mi mujer.

Puedo tener un ataque al corazón y, si lo tengo, no tendré a mis pastillas o a mi mujer para ayudarme.

En una escala del 0-100, indica su grado de probabili- $\quad 80 \%$

dad:

Después de la exposición

¿Pasó lo que más te preocupaba? Sí o No

No.

¿Cómo lo sabes?

Mi corazón no se paró, me mantuve consciente, y no noté ningún dolor.

¿Qué aprendiste?

Probablemente, no tendré ningún ataque al corazón o infarto, así que no necesito a mis pastillas, o que mi mujer esté presente, cada vez que tengo estas sensaciones físicas. 
Tabla 6. Estrategias para potenciar el aprendizaje inhibitorio

\begin{tabular}{|c|c|c|}
\hline Estrategia & Descripción & ¿Qué decir al paciente? \\
\hline Violación de expectativas & $\begin{array}{l}\text { Diseñar exposiciones para violar expectati- } \\
\text { vas específicas. }\end{array}$ & Pruébalo \\
\hline Extinción intensificada & $\begin{array}{l}\text { Presentar dos estímulos durante la misma } \\
\text { exposición después de llevar a cabo una ex- } \\
\text { tinción inicial con al menos uno de ellos. }\end{array}$ & Combínalo \\
\hline Extinción reforzada & $\begin{array}{l}\text { Presentar el EI ocasionalmente durante las } \\
\text { exposiciones. }\end{array}$ & Afronta tu miedo \\
\hline Variabilidad & Variar los estímulos y los contextos & Varíalo \\
\hline Retirar señales de seguridad & $\begin{array}{l}\text { Disminuir el uso de conductas o señales de } \\
\text { seguridad. }\end{array}$ & Tíralo \\
\hline Foco atencional & $\begin{array}{l}\text { Mantener la atención en el estímulo central } \\
\text { durante la exposición. }\end{array}$ & Quédate con ello \\
\hline Etiquetado de emociones & $\begin{array}{l}\text { Alentar a los clientes a describir su expe- } \\
\text { riencia emocional durante la exposición. }\end{array}$ & Dilo \\
\hline $\begin{array}{l}\text { Recuperación mental/ claves de recupera- } \\
\text { ción }\end{array}$ & $\begin{array}{l}\text { Usar un estímulo presentado durante la ex- } \\
\text { tinción o recordar otras exposiciones exito- } \\
\text { sas. }\end{array}$ & Recupéralo \\
\hline
\end{tabular}

do. Eso contribuye a la consolidación del nuevo aprendizaje sobre la relación no-contingente entre el estímulo condicionado y el estímulo incondicionado. Además, la exposición incluye "potenciación del aprendizaje inhibitorio y estrategias de potenciación de la regulación inhibitoria", incluyendo extinción intensificada (exposición a múltiples estímulos temidos), extinción reforzada ocasionalmente (exposición ocasional a consecuencias aversivas), desacostumbrarse al uso de señales de seguridad, variabilidad de estímulos y respuestas, claves de recuperación, contextos múltiples, y etiquetado de las emociones. La Tabla 6 resume estas estrategias juntamente con frases que consideramos útiles para expresar su objetivo a los clientes.

La aproximación a la exposición desde un enfoque moderno de la teoría del aprendizaje conlleva numerosas ventajas. En primer lugar, se puede dar una explicación parsimoniosa de los elementos compartidos por la exposición tradicional (o experimentos conductuales), a la vez que se explican sus limitaciones. En segundo lugar, se conecta la investigación clínica con la abundante investigación sobre la teoría del aprendizaje llevada a cabo en poblaciones animales y humanas. En tercer lugar, existe la posibilidad de mejorar la eficacia de los procedimientos basados en la exposición, centrándose de forma selectiva en los mecanismos de aprendizaje asociativo. Las teorías del aprendizaje asociativo proporcionan un modelo explicativo parsimonioso en el que enmarcar los procesos de exposición. Aun así, es necesaria más investigación translacional para determinar las condiciones óptimas que potencian la regulación inhibitoria y los métodos precisos para implementar estas estrategias en la asistencia clínica habitual.

\section{Referencias}

Agren, T., Engman, J., Frick, A., Bjőrkstrand, J., Larsson, E. M., Furmark, T., \& Fredrikson, M. (2012). Disruption of reconsolidation erases a fear memory trace in the human amygdala. Science, 21, 1550-1552.

Arch, J. J., \& Craske, M. G. (2009). First-line treatment: a critical appraisal of cognitive behavioral therapy developments and alternatives. Psychiatric Clinics of North America, 32, 525547.

Baker, A., Mystkowski, J., Culver, N., Yi, R., Mortazavi, A., \& Craske, M.G. (2010). Does habituation matter? Emotional processing theory and exposure therapy for acrophobia. Behaviour Research and Therapy, 48, 1139-1143.

Baker, K. D., McNally, G. P., \& Richardson, R. (2013). Memory retrieval before or after extinction reduces recovery of fear in adolescent rats. Learning \& Memory, 20, 467-473.

Bandarian Balooch. S., \& Neumann, D. L. (2011). Effects of multiple contexts and context similarity on the renewal of extinguished conditioned behaviour in an ABA design with humans. Learning and Motivation, 42, 53-63.

Bandarian Balooch. S., Neumann D., \& Boschen M. J. (2012). Extinction treatment in multiple contexts attenuates $\mathrm{ABC}$ renewal in humans. Behaviour Research and Therapy, 50, 604-9. 
Barlow, D. H., \& Craske, M. G. (1994). Mastery of your anxiety and panic II. Albany. NY: Graywind Publications Incorporated.

Beckers, T., Krypotos, A. M., Boddez, Y., Effting, M., \& Kindt, M. (2013). What's wrong with fear conditioning? Biological psychology, 92, 90-96.

Bjork, R. A., \& Bjork, E. L. (1992). A new theory of disuse and an old theory of stimulus fluctuation. En A. Healy, S. Kosslyn, R. Shiffrin (Eds.). From learning processes to cognitive processes: Essays in honor of William K. Estes. Hillsdale, NJ: Erlbaum.

Bjork, R. A. \& Bjork, E. L. (2006). Optimizing treatment and instruction: Implications of a new theory of disuse. En L.G. Nilsson \& N. Ohta (Eds.). Memory and society: Psychological Perspectives. New York: Psychology Press.

Bouton, M. E. (1993). Context, time, and memory retrieval in the interference paradigms of Pavlovian learning. Psychological Bulletin, 114, 80-99.

Bouton, M. E., Woods, A. M., \& Pineño, O. (2004). Occasional reinforced trials during extinction can slow the rate of rapid reacquisition. Learning and Motivation, 35, 371-390.

Bouton, M. E., \& King, D. A. (1983). Contextual control of the extinction of conditioned fear: tests for the associative value of the context. Journal of Experimental Psychology: Animal Behavior Processes, 9, 248-265.

Bouton, M. E., García-Gutiérrez, A., Zilkski, J., \& Moody, E. W. (2006). Extinction in multiple contexts does not necessarily make extinction less vulnerable to relapse. Behavior Research and Therapy, 44, 983-994.

Bouton, M. E., Westbrook, R. F., Corcoran, K. A., \& Maren, S. (2006). Contextual and temporal modulation of extinction: behavioral and biological mechanisms. Biological Psychiatry, 60, 352-360.

Brooks, D. C., \& Bouton, M. E. (1994). A retrieval cue for extinction attenuates response recovery (renewal) caused by a return to the conditioning context. Journal of Experimental Psychology: Animal Behavior Processes, 20, 366-379.

Cain, C. K., Blouin, A. M., \& Barad, M. (2004). Adrenergic transmission facilitates extinction of conditional fear in mice. Learning \& Memory, 11, 179-187.

Chan, W. Y., Leung, H.T., Westbrook, R.F., y McNally, G.P. (2010). Effects of recent exposure to a conditioned stimulus on extinction of Pavlovian fear conditioning. Learning \& Memory, 17, 512-521.

Clark, D. A., y Beck, A. T. (2010). Cognitive Therapy of Anxiety disorders: Science and Practice. New York, NY: Guilford Press.

Craske, M. G., Kircanski, K., Zelikowsky, M., Mystkowski, J., Chowdhury, N., y Baker, A. (2008). Optimizing inhibitory learning during exposure therapy. Behaviour Research and Therapy, 46, 5-27.

Craske, M. G., Liao, B., Brown, L., y Verliet, B. (2012). Role of inhibition in exposure therapy. Journal of Experimental Psychopathology, 3, 322-345.

Craske, M. G., \& Mystkowski, J. (2006). Exposure therapy and extinction: clinical studies. En M.G. Craske, D. Hermans, \& D. Vansteenwegen (Eds.). Fear and Learning: Basic Science to Clinical Application. Washington, DC: APA Books.
Craske, M.G., \& Rachman, S. (1986). Return of fear: Heart rate responsivity and perceived skill. British Journal of Clinical Psychology, 26, 187-199.

Craske, M. G., Waters, A. M., Bergman, L. R., Naliboff, B., Lipp, O. V., Negoro, H., \& Ornitz, E. M. (2008). Is aversive learning a marker of risk for anxiety disorders in children? Behaviour Research and Therapy, 46, 954-967.

Culver, N. C., Stephens, S., \& Craske, M. G. (en preparación-a). Occasional reinforced trials during extinction attenuates spontaneous recovery and rapid reacquisition.

Culver, N. C., Stoyanova, M., \& Craske, M. G. (2011). Clinical relevance of retrieval cues for attenuating context renewal of fear. Journal of Anxiety Disorders, 25, 284-292.

Culver, N., Stoyanova, M.S., \& Craske, M.G. (2012). Emotional variability and sustained arousal during exposure. Journal of Behavior Therapy and Experimental Psychiatry, 2, 783-793.

Culver, N. C., Vervliet, B., \& Craske, M. G. (en preparación-b). Compound stimulus presentation deepens extinction learning.

Davey, G. C. (1992). Classical conditioning and the acquisition of human fears and phobias: A review and synthesis of the literature. Advances in Behaviour Research and Therapy, 14, 29-66.

Deacon, B. J., Sy, J., Lickel, J. J., \& Nelson, E. O. (2010). Does the judicious use of safety behaviors improve the efficacy and acceptability of exposure therapy for claustrophobic fear? Journal of Behavior. Therapy and Experimental Psychiatry, 41, 71-80.

Deacon, B., Kemp, J. J., Dixon, L. J., Sy, J. T., Farrell, N. R., \& Zhang, A. R. (2013). Maximizing the efficacy of interoceptive exposure by optimizing inhibitory learning: A randomized controlled trial. Behaviour Research and Therapy, 51, 588-596.

Dibbets, P., Havermans, R., \& Arntz, A. (2008). All we need is a cue to remember: the effect of an extinction cue on renewal. Behaviour Research and Therapy, 46, 1070-1077.

Dibbets, P., \& Maes, J.H.R. (2011). The effect of an extinction cue on ABA-renewal: Does valence matter? Learning and Motivation, 42, 133-144.

Estes, W. K. (1955). Statistical theory of distributional phenomena in learning. Psychological Review, 62, 369-377.

Foa, E. B., \& Kozak, M. J. (1986). Emotional processing of fear: exposure to corrective information. Psychological Bulletin, 99, 20-35.

Foa, E. B., \& McNally, R. J. (1996). Mechanisms of change in exposure therapy. En R. M. Rapee (Ed.). Current controversies in the anxiety disorders (pp 214-227). New York, NY: Guilford Press.

Gallistel, C.R. \& Gibbon, J. (2000). Time, rate, and conditioning. Psychological Review, 107, 289-344.

Grillon, C. (2008). Models and mechanisms of anxiety: evidence from startle studies. Psychopharmacology, 199, 421-437.

Gunther, L. M., Denniston, J. C., \& Miller, R. R. (1998). Conducting exposure treatment in multiple contexts can prevent relapse. Behaviour Research and Therapy, 36, 75-91.

Hermans, D., Craske, M. G., Mineka, S., \& Lovibond, P. F. (2006). Extinction in human fear conditioning. Biological Psychiatry, 60, 361-368.

Hermans, D., Dirikx, T., Vansteenwegenin, D., Baeyens, F., Van den Bergh, O., \& Eelen, P. (2005). Reinstatement of fear responses in human aversive conditioning. Behaviour Research and Therapy, 43, 533-551. 
Hofmann, S. G., \& Smits, J. A. (2008). Cognitive-behavioral therapy for adult anxiety disorders: a meta-analysis of randomized placebo-controlled trials. Journal of Clinical Psychiatry, 69, 621-632.

Indovina, I., Robbins, T. W., Nunez-Elizalde, A. O., Dunn, B. D., \& Bishop, S. J. (2011). Fear conditioning mechanisms associated with trait vulnerability to anxiety in humans. Neuron, 10, 563-571.

Joos, E. (2011). Repetitive thought in human (fear) conditioning: Strengthening the acquisition and extinction memory. (Doctoral Dissertation).

Jovanovic, T., Norrholm, S. D., Blanding, N. Q., Davis, M., Duncan, E., Bradley, B., \& Ressler, K. J. (2010). Impaired fear inhibition is a biomarker of PTSD but not depression. Depression and Anxiety, 27, 244-51.

Kircanski, K., Mortazavi, A., Castriotta, N., Baker, A. S., Mystkowski, J. L., Yi, R., \& Craske, M. G. (2012). Challenges to the traditional exposure paradigm: Variability in exposure therapy for contamination fears. Journal of behavior therapy and experimental psychiatry, 43, 745-751.

Lader, M. H., \& Mathews, A. M. (1968). A physiological model of phobic anxiety and desensitization. Behaviour Research and Therapy, 6, 411-421.

Lang, A. J., \& Craske, M. G. (2000). Manipulations of exposure-based therapy to reduce return of fear: a replication. Behaviour Research and Therapy, 38, 1-12.

Lieberman, M. D., Eisenberger, N. I., Crockett, M. J., Tom, S. M., Pfeifer, J. H., \& Way, B. M. (2007). Putting Feelings Into Words. Psychological Science, 18, 421-428.

Lissek, S., Powers, A. S., McClure, E. B., Phelps, E. A., Woldehawariat, G., Grillon, C., \& Pine, D. S. (2005). Classical fear conditioning in the anxiety disorders: a meta-analysis. Behaviour Research and Therapy, 43, 1391-1424.

Lovibond, P. F., Davis, N. R., \& O'Flaherty, A. S. (2000). Protection from extinction in human fear conditioning. Behaviour Research and Therapy, 38, 967-983.

Mackintosh, N. J. (1975). A theory of attention: Variations in the associability of stimuli with reinforcement. Psychological Review, 82, 276-298.

Magill, R. A., \& Hall, K. G. (1990). A review of the contextual interference effect in motor skill acquisition. Human Movement Science, 9, 241-289.

Meeter, M., \& Murre, J. M. J. (2004). Consolidation of long-term memory: Evidence and

alternatives. Psychological Bulletin, 130, 843-857.

Meuret, A. E., Wolitzky-Taylor, K. B., Twohig, M. P., \& Craske, M. G. (2012). Coping skills and exposure therapy in panic disorder and agoraphobia: Latest advances and future directions. Behavior therapy, 43, 271-284.

Milad, M. R., Furtak, S. C., Greenberg, J. L., Keshaviah, A., Im, J. J., Falkenstein, M. J., ... Wilhelm, S. (2013). Deficits in conditioned fear extinction in obsessive-compulsive disorder and neurobiological changes in the fear circuit. JAMA, 70, 608618.

Milad, M. R., Pitman, R. K., Ellis, C. B., Gold, A. L., Shin, L. M., Lasko, N. B., ... Rauch, S. L. (2009). Neurobiological basis of failure to recall extinction memory in posttraumatic stress disorder. Biological Psychiatry, 66, 1075-1082.
Milad, M. R., Wright, C. I., Orr, S. P., Pitman, R. K., Quirk, G. J., \& Rauch, S. L. (2007). Recall of fear extinction in humans activates the ventromedial prefrontal cortex and hippocampus in concert. Biological Psychiatry, 62, 446-454.

Miller, R. R., \& Matzel, L. D. (1988). Contingency and relative associative strength. En S. B. Klein \& R. R. Mowrer (Eds.). Contemporary learning theories: Pavlovian conditioning and the status of traditional learning theory (pp. 61-84). Hillsdale, NJ: Lawrence Erlbaum Associates.

Mineka, S., Mystkowski, J.L., Hladek, D., Rodriguez, B.I. (1999). The effects of changing contexts on return of fear following exposure therapy for spider fear. Journal of Consulting and Clinical Psychology, 67, 599-604.

Monfils, M.H., Cowansage, K.K., Klann, E., \& LeDoux, J.E. (2009). Extinction-reconsolidation boundaries: key to persistent attentuation of fear memories. Science, 324, 951-955.

Myers, K. M., \& Davis, M. (2007). Mechanisms of fear extinction. Molecular Psychiatry, 12, 120-150.

Mystkowski, J. L., Craske, M. G., \& Echiverri, A. M. (2002). Treatment context and return of fear in spider phobia. Behavior Therapy, 33, 399-416.

Mystkowski, J. L., Craske, M. G., Echiverri, A. M., \& Labus, J. S. (2006). Mental reinstatement of context and return of fear in spider-fearful participants. Behavior Therapy, 37, 49-60.

Mystkowski, J. L., Mineka, S., Vernon, L. L., \& Zinbarg, R. E. (2003). Changes in caffeine states enhance return of fear in spider phobia. Journal of Consulting and Clinical Psychology, $71,243-250$.

Nader, K., Schafe, G. E., \& Le Doux, J. E. (2000). Fear memories require protein synthesis in the amygdala for reconsolidation after retrieval. Nature, 406, 722-206.

Neumann, D. L., Lipp, O. V., \& Cory, S. E. (2007). Conducting extinction in multiple contexts does not necessarily attenuate the renewal of shock expectancy in a fear-conditioning procedure with humans. Behaviour Research and Therapy, 45, 385394.

Norton, P. J., \& Price, E. C. (2007). A meta-analytic review of adult cognitive-behavioral

treatment outcome across the anxiety disorders. Journal of Nervous and Mental Disease, 195, 521-531.

Pearce, J. M., \& Hall, G. (1980). A model for Pavlovian learning: variations in the effectiveness of conditioned but not of unconditioned stimuli. Psychological review, 87, 532-552.

Plendl, W., \& Wotjak, C. T. (2010). Dissociation of within-and between-session extinction of conditioned fear. The Journal of Neuroscience, 30, 4990-4998.

Podina, I. R., Koster, E.H., Philippot, P., Dethiuer, V., \& David, D.O. (2013). Optimal attentional focus during exposure in specific phobia: a meta-analysis. Clinical Psychology Review, 33, 1172-1183.

Ponnusamy, R., Zhuravka, I., Poulos, A.M., Huang, J., Wolvek, D., O’Neil, P.K., \& Fanselow, M.S. (August 2011). Retrieval vs Reconsolidation accounts of deepened extinction with reminder treatments. Poster presented at the Gordon Research Conference.

Prenoveau, J. M., Craske, M. G., Liao, B., \& Ornitz, E. M. (2013). Human fear conditioning and extinction: Timing is everything...or is it? Biological psychology, 92, 59-68. 
Quirk, G. J. (2002). Memory for extinction of conditioned fear is long-lasting and persists following spontaneous recovery. Learning \& Memory, 9, 402-407.

Rachman, S., Shafran, R., Radomsky, A. S., \& Zysk, E. (2011). Reducing contamination by exposure plus safety behaviour. Journal of Behavior Therapy and Experimental Psychiatry, 42, 397-404.

Rescorla, R.A. (2000). Extinction can be enhanced by a concurrent excitor. Journal of

Experimental Psychology, 26, 251-260.

Rescorla, R. A. (2006). Deepened extinction from compound stimulus presentation. Journal of Experimental Psychology: Animal Behavior Processes, 32, 135-144.

Rescorla, R. A., \& Heth, C. D. (1975). Reinstatement of fear to an extinguished conditioned stimulus. Journal of Experimental Psychology: Animal Behavior Processes, 1, 88-96.

Rescorla, R. A., \& Wagner, A. R. (1972). A theory of Pavlovian conditioning: Variations in the effectiveness of reinforcement and non-reinforcement. En Prokasy A.H. (Ed.). Classical Conditioning II: Current Research and Theory (pp 64-99). New York: Appleton-Century-Croft.

Ricker, S. T., \& Bouton, M. E. (1996). Reacquisition following extinction in appetitive conditioning. Animal Learning \& Behavior, 24, 423-436.

Rodriguez, B.I., Craske, M.G., Mineka, S., \& Hladek, D. (1999). Context-specificity of relapse: effects of therapist and environmental context on return of fear. Behaviour Research and Therapy, 37, 845-862.

Rougemont-Bucking, A., Linnman, C., Zeffiro, T. A., Zeidan, M. A., Lebron-Milad, K., Rodriguez-Romaguera, J., ... Milad, M. R. (2011). Altered processing of contextual information during fear extinction in PTSD: an fMRI study. CNS Neuroscience \& Therapeutics, 17, 227-236.

Rowe, M. K. \& Craske, M. G. (1998). Effects of varied-stimulus exposure training on fear reduction and return of fear. Behaviour research and therapy, 36, 719-734.

Salkovskis, P. M. (1991). The importance of behaviour in the maintenance of anxiety and panic: a cognitive account. Behavioural Psychotherapy, 19, 6-19.

Salkovskis, P. M., Hackmann, A., Wells, A., Gelder, M.G., Clark, D.A. (2006). Belief disconfirmation versus habituation approaches to situational exposure in panic disorder with agoraphobia: A pilot study. Behaviour Research and Therapy, 45, 877-885.

Schiller, D., Monfils, M.H., Raio, C.M., Johnson, D.C., LeDoux, J.E., Phelps, E.A. (2010). Preventing the return of fear in humans using reconsolidation update mechanisms. Nature, 463 , 49-53.
Schmidt, R. A., \& Bjork, R. A. (1992). New conceptualization of practice: common principles in three paradigms suggest new concepts for training. Psychological Science, 3, 207-217.

Shea, J.B., Morgan, R.L. (1979). Contextual interference effects on the acquisition, retention, and transfer of a motor skill. Journal of Experimental Psychology: Human Learning and Memory, 5, 179-187.

Shin, L. M., \& Liberzon, I. (2010). The neurocircuitry of fear, stress, and anxiety disorders. Neuropsychopharmacology, 35, 169-91.

Sloan, T., \& Telch, M. J. (2002). The effects of safety-seeking behavior and guided threat reappraisal on fear reduction during exposure: an experimental investigation. Behaviour Research and Therapy, 40, 235-251.

Sy, J. T., Dixon, L. J., Lickel, J. J., Nelson, E. A., \& Deacon, B. J. (2011). Failure to replicate the deleterious effects of safety behaviors in exposure therapy. Behaviour Research and Therapy, 49, 305-314.

Tabibnia, G., Lieberman, M. D., \& Craske, M. G. (2008). The lasting effect of words on feelings: Words may facilitate exposure effects to threatening images. Emotion, 8, 307-317.

Tsao, J.C.I., \& Craske, M.G. (2000). Timing of treatment and return of fear: Effects of massed, uniform, and expanding spaced exposure schedules. Behavior therapy, 31, 479-497.

Tsodyks, M., \& Gilbert, C. (2004). Neural networks and perceptual learning. Nature, 431, 775-781.

Van Damme, S., Crombez, G., Hermans, D., Koster, E. H., \& Eccleston, C. (2006). The role of extinction and reinstatement in attentional bias to threat: a conditioning approach. Behaviour Research and Therapy, 44, 1555-1563.

Vansteenwegen, D., Vervliet, B., Hermans, D., Beckers, T., Baeyens, F., \& Eelen, P. (2006). Stronger renewal in human fear conditioning when tested with an acquisition retrieval cue than with an extinction retrieval cue. Behaviour Research and Therapy, 44, 1717-1725.

Vansteenwegen, D., Vervliet, B., Iberico, C., Baeyens, F., Van den Bergh, O., \& Hermans, D. (2007). The repeated confrontation with videotapes of spiders in multiple contexts attenuates renewal of fear in spider-anxious students. Behaviour Research and Therapy, 45, 1169-1179.

Vervliet, B., Craske, M.G., and Hermans, D. (2013). Fear Extinction and Relapse: State of the Art. Annual Review of Clinical Psychology, 9, 215-248.

Wagner, A. R. (1981). SOP: A model of automatic memory processing in animal behavior. En N. E. Spear, \& R. R. Miller (Eds.). Information processing in animals: Memory mechanis$m s$. Hillsdale, NJ: Erlbaum

Wolpe, J. (1958). Psychotherapy by reciprocal inhibition. Stanford: Stanford University Press. 